\title{
Thioxanthone Derivatives as a New Class of Organic Photocatalysts for Photopolymerisation Processes and the 3D Printing of Photocurable Resins under Visible Light
}

\author{
Emilia Hola ${ }^{1}$, Maciej Pilch ${ }^{1}$ and Joanna Ortyl ${ }^{1,2, *(D)}$ \\ 1 Faculty of Chemical Engineering and Technology, Cracow University of Technology, Warszawska 24, \\ 31-155 Cracow, Poland; emilia.hola@doktorant.pk.edu.pl (E.H.); pilchmac@gmail.com (M.P.) \\ 2 Photo HiTech Ltd., Bobrzyńskiego 14, 30-348 Cracow, Poland \\ * Correspondence: jortyl@pk.edu.pl
}

Received: 1 July 2020; Accepted: 4 August 2020; Published: 8 August 2020

check for updates

\begin{abstract}
In the present paper, novel thioxanthone-based compounds were synthesised and evaluated as a component of photoredox catalysts/photoinitiating systems for the free-radical polymerisation (FRP) of acrylates and the ring-opening cationic polymerisation (CP) of epoxy monomers. The performance of the obtained thioxanthones in two- and three-component photoinitiating systems, in combination with amines, iodonium or sulphonium salt, as well as with alkyl halide, for photopolymerisation processes upon exposure to light emitting diodes (LEDs) with a maximum emission of $405 \mathrm{~nm}$ and $420 \mathrm{~nm}$, was investigated. The studied compounds act also as one-component free-radical photoinitiators. Fourier transform real-time infrared spectroscopy was used to monitor the kinetics of disappearance of the functional groups of the monomers during photoinitiated polymerisation. Excellent photoinitiating efficiency and high final conversions of functional groups were observed. Moreover, the influence of thioxanthone skeleton substitution on photoinitiating efficiency was discussed. The photochemical mechanism was also investigated through cyclic voltammetry. It was discovered that thioxanthone derivatives can be used as a metal-free photoredox catalyst active for both oxidative and reductive cycles. Furthermore, a photopolymerizable system based on novel thioxanthone derivatives in a stereolithography three-dimensional (3D) printing technology under visible sources of light was used. The effects of photoinitiator type system and monomer type in photoresins during 3D printing processes were explored. The outcome of this research is the development of high-performance visible photosensitive resins with improved photosensitivity obtained thanks to the development of entirely novel photoinitiating systems specifically adapted for this application.
\end{abstract}

Keywords: photopolymerisation; free-radical photopolymerisation; cationic photopolymerisation; photoinitiators; photocatalysts; photoinitiating systems; 3D printing; thioxanthone

\section{Introduction}

Polymerisation initiated by visible light is considered to be an eco-friendly and sustainable alternative to traditional thermal polymerisation [1,2]. Photoinduced processes possess a lot of attractive features-mild reaction conditions, nearly no release of volatile organic compounds (VOCs), and room temperature operation with the use of convenient light sources [3]. Recently, there have been many developments in the field of photochemistry-especially in new monomers [4,5]—for monitoring on-line and/or in-situ processes of photopolymerisation [6-8], as well as completely new highly efficient photoinitiating systems, which are necessary for photopolymerisation processes [9-11]. 
The search for new, effective components for initiating systems operating in visible light has drawn the attention of scientists from around the world [12]. Recently, light-emitting diodes (LEDs) have attracted increased attention as potential irradiation sources for photopolymerisation processes substituting traditional mercury UV lamps and enabling processes carried out in visible light. LED technology is known for its fast development, and holds great promise. The characteristic features of UV-LEDs and Vis-LEDs are low energy consumption, no ozone release, low heat generation, low operating costs, low maintenance, long lifetime, easily controlled intensity and, more important, they are small, compact machines with easy and safe handling $[13,14]$.

Photopolymerisation processes can be divided, according to their mechanism, to cationic and free radical reactions. The most popular initiators for cationic polymerisations are onium salts, and these processes have become well established in commercial applications and academic research $[15,16]$. From a practical point of view, iodonium and sulphonium salts are the most utilised cationic photoinitiators [17]. Photolysis of onium salts occurs through both heterolytic or homolytic cleavage of the photoexcited onium salt resulting in the formation of cation or radical cation species. Most onium salts absorb light in the short wavelength region of the UV spectrum around $300 \mathrm{~nm}$. In order to enable the photolysis of onium salt in the visible region of the electromagnetic spectrum, photosensitization by appropriate compounds through electron [18] or energy transfer was proposed [19]. This process is regulated by the redox potentials of initiators and photosensitizers, and thermodynamics parameters.

Free radical photoinitiators can be subdivided into two categories depending on their decomposition mechanism: Type I photoinitiators, which undergo decomposition directly after irradiation of light to yield radicals that can initiate polymerisation; and Type II photoinitiators, which require a co-initiator, usually an amine, and functional groups that can readily have hydrogen abstracted, in addition to the photoinitiator. Initiation with Type I, with direct fragmentation of photoinitiators, contains bonds with a dissociation energy lower than that of the excited state, for example, benzoin derivatives [20-22], benzyl derivatives [23] and dialkoxyacetophenones [24]. In Type II, photoinitiators generate radicals in the multi-step reaction mechanism, undergo photoexcitation followed by an electron or hydrogen transfer process and, consequently, form initiating radical species [25]. Typical examples of commercially available Type II initiators include benzophenone [26], camphorquinone [27] as well as thioxanthone [28] and their derivatives, which are characterised by broad wavelength absorption in the near UV range of the electromagnetic spectrum [29].

The thioxanthone-based compounds in combination with amines are described in the literature and have been widely used as photoinitiators for free radical polymerisation, and less frequently for cationic polymerisations [30]. Therefore, for example, 2-methylol-thioxanthone [31] and thioxanthone based 9-[2-(methyl-phenyl-amino)-acetyl]-thia-naphthacene-12-one [32] were used as photoinitiators in combination with $N$-methyldiethanolamine (MDEA) for the free radical polymerisation of methyl methacrylate (MMA) in the presence of air. Derivatives of thioxanthone were also subjected to various condensation reactions to obtain conjugated systems, for example thioxanthone-anthracene compounds were applied to initiate the polymerisation of methyl methacrylate [33-35]. Heterocyclic extended thioxanthones-thioxanthone linked with benzothiophene, dibenzothiophene or benzotriazole moiety-were also studied as photoinitiators for the polymerisation of methyl methacrylate in the presence of amine [36,37]. There are also many reports in the literature concerning one-component initiators based on the thioxanthone skeleton. One-component Type II photoinitiators form initiating species through intramolecular and/or intermolecular interactions between the chromophore core and the co-initiator part of the photoinitiator without the need for additional substances. An interesting example can be 2-mercaptothioxanthone, a thiol substituted derivative of thioxanthone. This compound has been extensively utilised as an efficient one-component Type II photoinitiator for both acrylate and styrene monomers in the presence and absence of air [38]. The same molecule, 2-mercaptothioxanthone, has beneficial effects as an additive for acyl- and bisacylphosphine oxide photoinitiator formulations on the polymerisation of methacrylates. Acetic acid-based thioxanthone ( $\mathrm{TXCH} 2 \mathrm{COOH}$ ) was synthesised, characterised and used as a photoinitiator 
for the free radical photopolymerisation of methyl methacrylate in the absence and presence of a tertiary amine ( $N$-methyldiethanolamine-MDEA) in different solvents [39,40]. Glycine-functionalised thioxanthone, which possesses absorption across the entire visible region, was used as a free radical photoinitiator alone, as well as in the presence of amines, e.g., MDEA or $N$-phenylglycine (NPG). On the basis of scientific research, it has been shown that the addition of amine to glycine-functionalised thioxanthone increased photopolymerisation efficiency [41]. Several other nitrogen-containing one-component photoinitiators could successfully initiate the photopolymerisation of 1,6-hexanedioldiacrylate (HDDA), trihydroxymethylpropyl triacrylate (TMPTA) and pentaerythritol triacrylate (PETA) under xenon light exposure in the visible range $(\lambda>400 \mathrm{~nm})$ both in the presence and absence of $N$-methyldiethanolamine (MDEA) [42]. Thioxanthone-based one-component visible initiator 9-(2-morpholine-4yl-acetyl)-5-thia-naphthacen-12-one was also synthesised and used in the polymerisation of methyl methacrylate [43]. The thioxanthone core was also incorporated to polymeric photoinitiators-macroinitiators. Yin et al. developed a macroinitiator with thioxanthone and amine in its structure, which enables the use of this compound as a one-component photoinitiator for the free radical polymerisation of the monofunctional monomer MMA, the difunctional monomer poly(propylene glycol) diacrylate (PPGDA) and the trifunctional monomer TMPTA [44,45]. The TX derivative possessing an additional carbazole chromophore initiates the polymerisation of MMA or TMPTA in the absence and presence of a hydrogen donor [46]. Thioxanthone condensed with carbazole was also studied as a one-component Type II photoinitiator [47]. As thioxanthone derivatives with carbazole moiety in combination with tertiary amine are excellent initiators for free radical photopolymerisation (FRP), the reactivity of thioxanthones condensed with carbazole moiety was also investigated in free radical promoted cationic polymerisation [48]. Thioxanthone containing disilylacetylene acts as a Type I and Type II photoinitiator and guarantees efficient free radical polymerisation in air. This compound was also investigated in free radical promoted cationic polymerisation (FRPCP) [49]. Thioxanthone-based compounds, due to their absorption properties, are also utilised in many different areas, e.g., chiral thioxanthone can be used as an organocatalyst for enantioselective intramolecular [2 +2 ] photocycloaddition reactions induced by visible light [50]. Moreover, $\pi$-expanded thioxanthones are applied as sensitizers for lanthanide-based luminescent probes with visible excitation [51].

Increased requests for new photoinitiators with absorption characteristics from visible range, as well as the ability to act under soft irradiation sources of light, e.g., visible LEDs, have motivated us to synthesise novel thioxanthone derivatives. Therefore, the present work describes the systematic study of five new thioxanthone-based compounds, namely thioxanthone derivatives with 4-(diphenylamine)phenyl substituents and carbazole-based substituents in position 7 of 2,4-diethylthioxanthen-9-one. Thus, compounds consisting of two chromophoric parts were developed. Carbazole derivatives are themselves well-known additives in photopolymerisation processes, e.g., $\mathrm{N}$-vinylcarbazole (NVK) [52,53] and 9H-carbazole-9-ethanol (CARET) [54,55]. Carbazole derivatives $[56,57]$ were also used as photoinitiators/photoredox catalysts in initiating systems for $3 \mathrm{D}$ printing technology. Their interesting absorption properties in the visible region made these compounds worth investigating. An important part of our continuous interest in the field is the development of new photoinitiating systems capable of simultaneously initiating both cationic and radical photopolymerisation processes. Investigated 2,4-diethylthioxanthen-9-one derivatives are proposed as:

(i) Photosensitizers in bimolecular photoinitiating systems for cationic polymerisation;

(ii) Photosensitizers in bimolecular photoinitiating systems for free-radical polymerisation;

(iii) One-component free-radical photoinitiators for polymerisation of acrylate monomer;

(iv) Type II photoinitiators for polymerisation of acrylate monomer.

Thus, we also described the potential application of the investigated thioxanthone derivatives as organic photoinitiating catalysts thanks to which the developed compounds can be universally 
used in a wide spectrum of applications in photoinduced processes of polymerisation, e.g., 3D printing technology.

\section{Results and Discussion}

\subsection{Light Absorption Properties of 2,4-Diethyl-thioxanthen-9-one Derivatives}

The UV-Vis absorption spectra of 2,4-diethyl-thioxanthen-9-one derivatives in acetonitrile are given in Figure 1a, and their spectroscopic data absorption maxima and molar extinction coefficients are summarised in Table 1. The investigated compounds (Scheme 1) are characterised by high molar extinction coefficients. In particular, the absorption of thioxanthone derivatives is excellent in the 350-450 nm spectral range ensuring an overlap with the emission spectra of the Vis LEDs $405 \mathrm{~nm}$ and $420 \mathrm{~nm}$. The fact that the absorption spectra of the studied compounds are redshifted in comparison to the commercially used sensitizer-DETX-is of great importance. The modification of 2,4-diethylthioxanthen-9-one through the introduction of diphenylamine or carbazole substituents has a positive impact on the absorption properties of synthesised compounds. Compound T1 possesses the most redshifted absorption spectrum. The absorption characteristics of compounds with carbazole substituents are in the same region, while the molar extinction coefficient $\varepsilon_{\mathrm{T} 3}>\varepsilon_{\mathrm{T} 4}>\varepsilon_{\mathrm{T} 2}>\varepsilon_{\mathrm{T} 5}$ differs. The overlaps between the emission spectra of the LED with maximum emission at $405 \mathrm{~nm}$ and the LED with maximum at $420 \mathrm{~nm}$ with the absorption spectra of 2,4-diethyl-thioxanthen-9-one derivatives make them interesting as potential visible light sensitizers. The absorption spectra of initiators and other components of the studied initiating systems are presented in Figure 1b. It is worth mentioning that none of these substances absorb above $360 \mathrm{~nm}$.

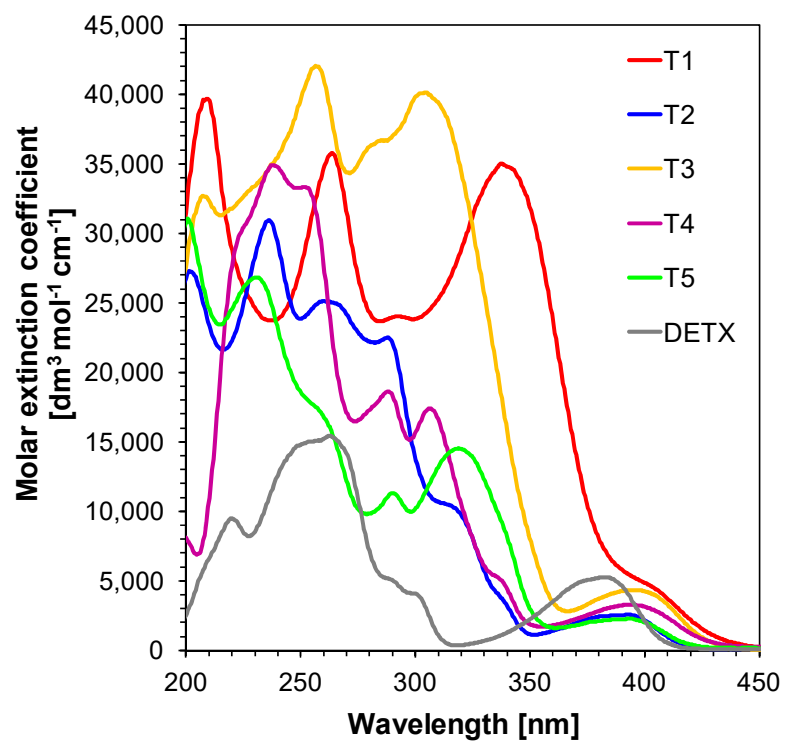

(a)

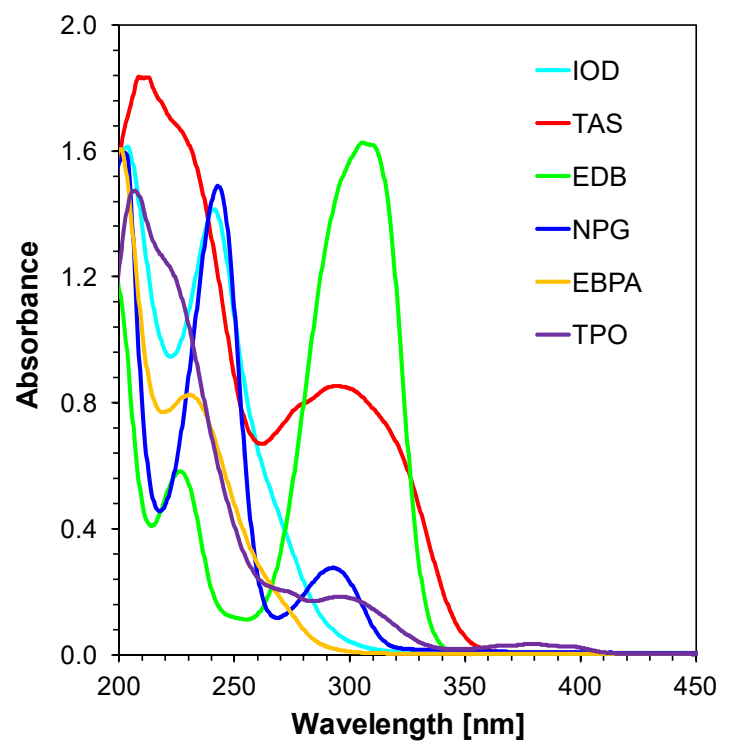

(b)

Figure 1. (a) Absorption properties of 2,4-diethyl-thioxanthen-9-one derivatives in acetonitrile. (b) Absorption properties of onium salts and other additives used as components for photoinitiating systems: IOD—bis(4-t-butylphenyl)-iodonium hexafluorophosphate, TAS—triarylsulfonium hexafluorophosphate salts, EDB-ethyl 4-(dimethylamino)benzoate, NPG-N-phenylglycine, EBPAethyl $\alpha$-bromophenylacetate, TPO—diphenyl(2,4,6-trimethylbenzoyl)phosphine oxide. 
Table 1. Light absorption data of 2,4-diethyl-thioxanthen-9-one derivatives in acetonitrile: maximum absorption wavelengths $\left(\lambda_{\text {max-abs }}\right)$, molar extinction coefficients $(\varepsilon)$ at $\lambda_{\max }$ and the maximum of the emission wavelengths of the LEDs $405 \mathrm{~nm}$ and $420 \mathrm{~nm}$.

\begin{tabular}{cccccc}
\hline \multirow{2}{*}{ Compound } & $\begin{array}{c}\text { Concentration } \\
{\left[\mathbf{m o l} \cdot \mathbf{d m}^{-3}\right]}\end{array}$ & $\lambda_{\text {max-abs }}[\mathbf{n m}]$ & $\varepsilon_{\text {max }}$ & $\varepsilon_{405} \mathbf{~ n m}$ & $\varepsilon_{420 ~ \mathbf{~ m}}$ \\
\cline { 4 - 6 } & $4.03 \times 10^{-5}$ & 338 & 34,923 & 4405 & 2204 \\
T1 & $2.24 \times 10^{-5}$ & 393 & 2553 & 1615 & 268 \\
T2 & $4.40 \times 10^{-5}$ & 396 & 4329 & 3942 & 1598 \\
T3 & $3.60 \times 10^{-5}$ & 393 & 33,312 & 2892 & 1334 \\
T4 & $2.75 \times 10^{-5}$ & 393 & 2261 & 1644 & 432 \\
T5 & $9.70 \times 10^{-5}$ & 382 & 5263 & 1116 & 134 \\
DETX & $6.54 \times 10^{-5}$ & 241 & - & - & - \\
IOD & $3.42 \times 10^{-2} *$ & 294 & - & - & - \\
TAS & $6.83 \times 10^{-5}$ & 306 & - & - & - \\
EDB & $1.53 \times 10^{-4}$ & 293 & - & - & - \\
NPG & $1.53 \times 10^{-4}$ & 231 & - & - & - \\
EBPA & $6.60 \times 10^{-5}$ & 298 & - & - & - \\
TPO & & 380 & & & - \\
\hline
\end{tabular}

* Percentage concentration [\%] of TAS in acetonitrile (Triarylsulfonium hexafluorophosphate salts, mixed, 50\% in propylene carbonate).

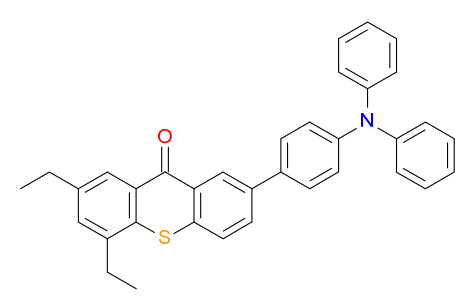

$\mathrm{T} 1$<smiles>CCc1cc(CC)c2sc3ccc(-c4cccc(-n5c6ccccc6c6ccccc65)c4)cc3c(=O)c2c1</smiles>

T2
T3
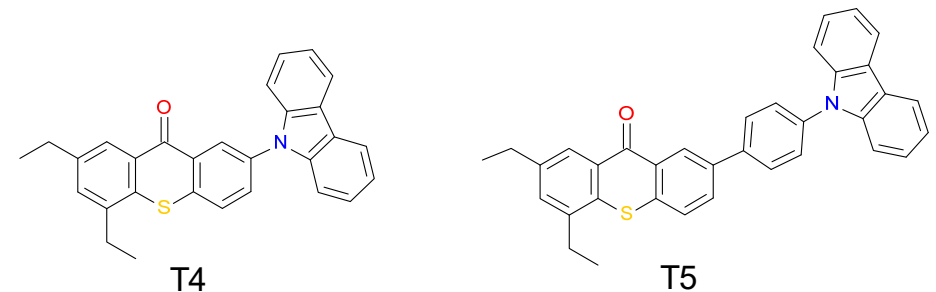

Scheme 1. 2,4-diethyl-thioxanthen-9-one derivatives studied in this work.

Scheme 2 presents the energy diagram of HOMO and LUMO (Highest Occupied Molecular Orbital and Lowest Unoccupied Molecular Orbital) in the molecules of the analysed diethylthioxanthone derivatives together with the determined energy gaps. It can be seen that the HOMO-LUMO energy gap for the unsubstituted diethylthioxanthone molecule (DETHX) is slightly larger than for the substituted structures (T1-T5). It is also worth noting that the energies of HOMO and LUMO orbitals in the molecule of unsubstituted diethylthioxanthone (DETHX) are about $0.5 \mathrm{eV}$ lower than for structures substituted with nucleophilic groups (T1-T5). This predicts greater stability for both ground and excited states of the diethylthioxanthone molecule (DETHX) relative to the substituted structures (T1-T5). The difference of HOMO orbital energy between the basic and substituted molecules in combination with redox properties of these molecules in excited states can be considered as a quantitative measure of the ability of the excited molecule to donate electrons during the electron transfer process. 


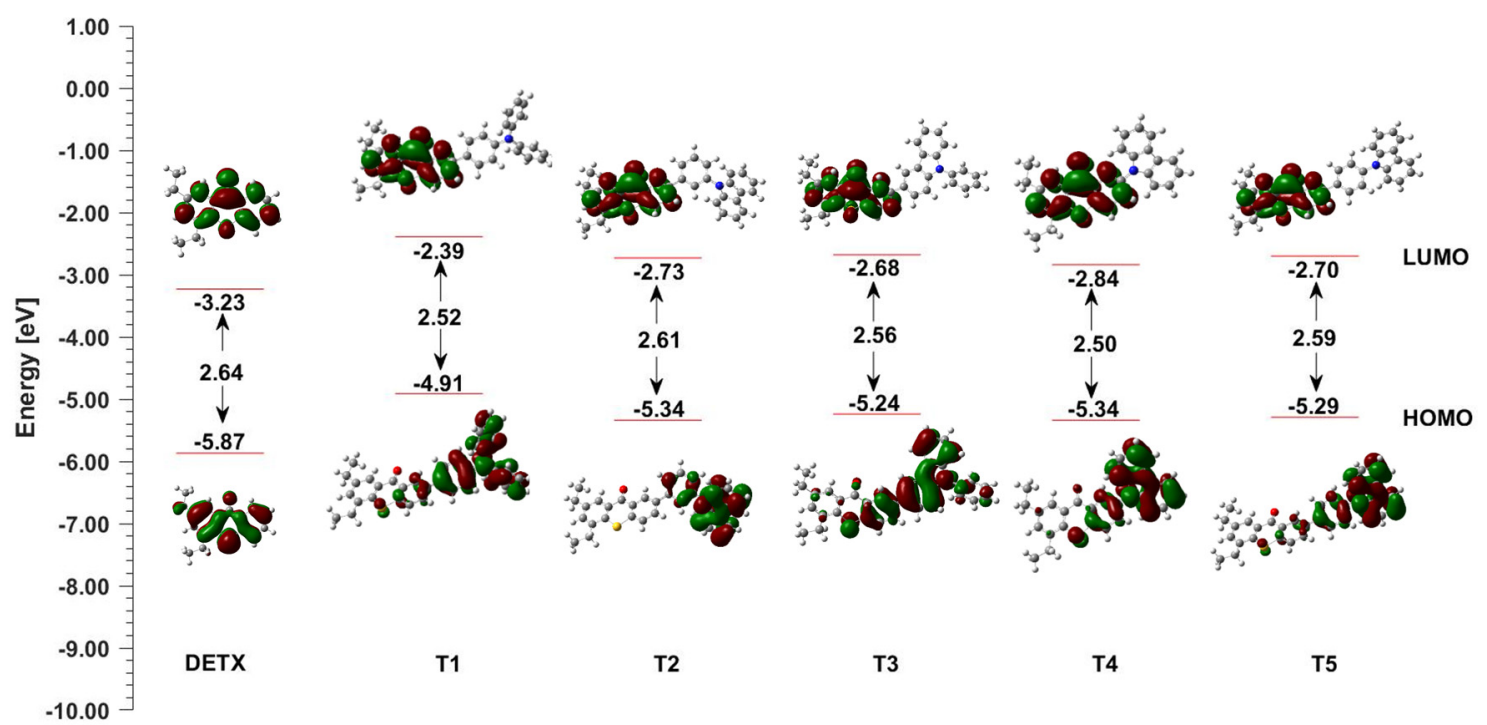

Scheme 2. Presentation of the energy levels, HOMO-LUMO gap and orbital composition distribution of the HOMO and LUMO for compounds T1-T5.

It is known that in bimolecular photoinitiating systems based on onium salts, the photosensitizer first absorbs the light and is then excited from the ground state to the excited state, which transfers electrons to the onium salt [58]. The system's ability to undergo such transformation is affected by two basic parameters characterising the photosensitizer. The first of these parameters is the oxidation potential of the photosensitizer. Based on the results of computer simulations presented above, it can be concluded that substitution of the diethylthioxanthone (DETX) molecule with nucleophilic groups, such as triphenylamine (T1), and groups containing aromatic nitrogen (T2-T5) causes the HOMO orbitals to shift towards the nucleophilic group. Increasing the electron density in one part of the molecule potentially reduces its oxidation potential, which has a positive effect on the ability of the sensitizer to transfer electrons to the onium salt. This relation was confirmed empirically on the basis of electrochemical tests described below, where it was shown that all analysed diethylthioxanthone derivatives (T1-T5) show much lower oxidation potential compared to the unsubstituted structure. The second of these parameters is the HOMO-LUMO energy gap. As mentioned earlier, it can be noticed that DETX shows a slightly higher value of the energy gap compared to the substituted structures (T1-T5). Due to this, the electron transfer process from the unsubstituted diethylthioxanthone molecule (DETX) is more favourable. The cumulative impact of both of these parameters on the thermodynamic ability of the photosensitizer-photoinitiator system to transfer electrons is determined by the parameter called Gibbs energy, which was calculated for the analysed molecules on the basis of experimental studies presented earlier. The obtained values of this parameter show that the electron transfer process for diethylthioxanthone molecules substituted with nucleophilic groups (T1-T5) is more favoured by thermodynamic than for unsubstituted molecules.

The photoinitiating efficiency of photoinitiator systems is associated with three factors. Firstly, absorption properties of the photosensitizers have an impact of performance of photopolymerization processes. Significant influence on the value of the final conversion after photopolymerization, is the oxidation potential of the photosensitizers. Value of free energy changes from the excited state $\left(\Delta G_{e t}\right)$ associated with an electron transfer between components of photoinitiating system is also important and will be described in detail in Section 2.4.

\subsection{Performance of 2,4-Diethyl-thioxanthen-9-one Derivatives as Photosensitizers in Bimolecular Photoinitiating Systems for Cationic Photopolymerisation}

Cationic polymerisation finds application in many areas. The most popular initiators for cationic polymerisation are iodonium and sulphonium salts. These initiators differ in their absorption 
properties (IOD-bis(4-t-butylphenyl)-iodonium hexafluorophosphate absorbs up to $\sim 320 \mathrm{~nm}$, TAS - triarylsulfonium hexafluorophosphate salts absorb up to $\sim 360 \mathrm{~nm}$-Figure 1b) but also in their reduction potentials. Triarylsulphonium salts have more negative values of reduction potentials than diaryliodonium salts. Iodonium salts can be easily photosensitized by a variety of different compounds, but not every compound which is able to sensitize iodonium salt is able to sensitize sulphonium salt [17]. Photosensitizers for sulphonium salts are limited to those with very low oxidation potentials. In this work, 2,4-diethyl-thioxanthen-9-one derivatives are proposed as highly efficient photosensitizers of iodonium, as well as sulphonium salts. Therefore, the next step was to conduct comprehensive research on the photoinitiating ability of the received thioxanthone derivatives during ring-opening cationic photopolymerisation of epoxy monomers. For this purpose, cationic polymerisation of UVACURE ${ }^{\circledR} 1500$ in thin films was performed under air in the presence of bimolecular photoinitiating systems consisting of 2,4-diethyl-thioxanthen-9-one derivatives and iodonium salt (IOD) or triarylsulphonium salt (TAS) respectively. The appropriate light emitting diodes (LEDs) with the maximum of emission localised at $405 \mathrm{~nm}$ or $420 \mathrm{~nm}$ were selected as visible light sources for the photopolymerisation processes. Additionally, DETX/TAS and DETX/IOD were tested as reference photoinitiating systems under the same experimental conditions. The typical conversion-time profiles are given in Figures 2 and 3, and the final epoxy conversion of the UVACURE ${ }^{\circledR} 1500$ monomer after $800 \mathrm{~s}$ of irradiation with LED sources with emission at $\lambda_{\max }=405 \mathrm{~nm}$ or $\lambda_{\max }=420 \mathrm{~nm}$ is summarised in Table 2. No polymerisation is observed under visible light irradiation when IOD or TAS are used alone, because of their limited absorption properties (up to $300 \mathrm{~nm}$ for IOD and up to $350 \mathrm{~nm}$ for TAS).

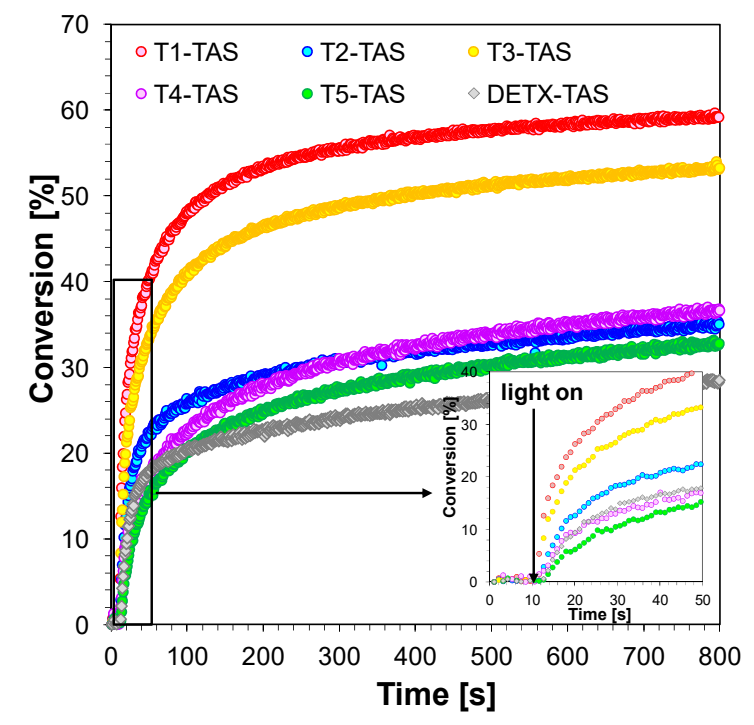

(a)

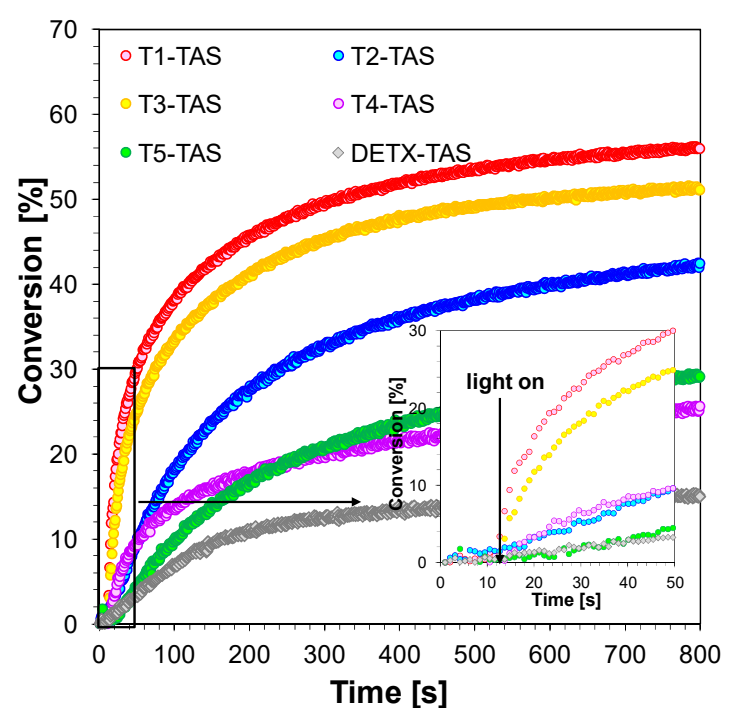

(b)

Figure 2. Polymerisation profiles of UVACURE ${ }^{\circledR} 1500$ (epoxy function conversion vs. irradiation time) under air in the presence of different photoinitiating systems based on TAS $(2 \% w / w)$ and 2,4-diethyl-thioxanthen-9-one derivatives $(0.2 \% w / w)$ upon exposure to (a) the visible LED@405 nm (b) the visible LED@420 nm. The irradiation starts at $\mathrm{t}=10 \mathrm{~s}$.

The cationic polymerisation of epoxy monomers occurs in the presence of the studied thioxanthone derivatives as photosensitizers and sulphonium or iodonium salts. The best photoinitiating abilities (rate of polymerisation and final conversion) in ring-opening cationic photopolymerisation in the presence of bimolecular photoinitiating systems consisting in thioxanthone derivatives and TAS $(0.2 \% / 2 \% w / w)$ combinations upon exposure to LED with emission at $\lambda_{\max }=405 \mathrm{~nm}$ are exhibited by the following compounds: 2,4-diethyl-7-[4-(N-phenylanilino)phenyl]thioxanthen-9-one (T1) and 2,4-diethyl-7-(9-phenylcarbazol-3-yl)thioxanthen-9-one (T3) (FC $=59 \%$ and $\mathrm{FC}=53 \%$ respectively). This is in agreement with the fact that these compounds are characterised by the highest values of molar 
extinction coefficients at $\lambda_{\max }=405 \mathrm{~nm}\left(\varepsilon_{\mathrm{T} 1}=4404\left[\mathrm{dm}^{3} \cdot \mathrm{mol}^{-1} \cdot \mathrm{cm}^{-1}\right], \varepsilon_{\mathrm{T} 3}=3942\left[\mathrm{dm}^{3} \cdot \mathrm{mol}^{-1} \cdot \mathrm{cm}^{-1}\right]\right)$. The photoinitiating performance of other sensitizers (7-(3-carbazol-9-ylphenyl)-2,4-diethyl-thioxanthen9-one (T2), 7-carbazol-9-yl-2,4-diethyl-thioxanthen-9-one (T4) and 7-(4-carbazol-9-ylphenyl)-2,4-diethylthioxanthen-9-one (T5)) is at a similar level with slightly lower final conversions around 35\%-Figure 2a. Remarkably, upon exposure to LED with emission at $\lambda_{\max }=420 \mathrm{~nm}$, the trend is in line with the results obtained with LED with emission at $\lambda_{\max }=405 \mathrm{~nm}$ as a light source. T1 and T3 are the most effective. Polymerisation in the presence of T1/TAS or T3/TAS starts directly after the light source was turned on and reached high final conversions at $56 \%$ and $51 \%$ respectively (Figure $2 \mathrm{~b}$ ). All investigated systems are better than the photoinitiating system based on 2,4-diethylthioxanthen-9-one (DETX/TAS) both with LED with $\lambda_{\max }=405 \mathrm{~nm}$ and $\lambda_{\max }=420 \mathrm{~nm}$. The final monomer conversions are equal to $28 \%$ and $15 \%$ respectively. This can be associated with the electrochemical properties of 2,4-diethylthioxanthen-9-one (DETX) and the thermodynamics of electron transfer between DETX and TAS (as discussed below). The final conversion values are summarised in Table 2.

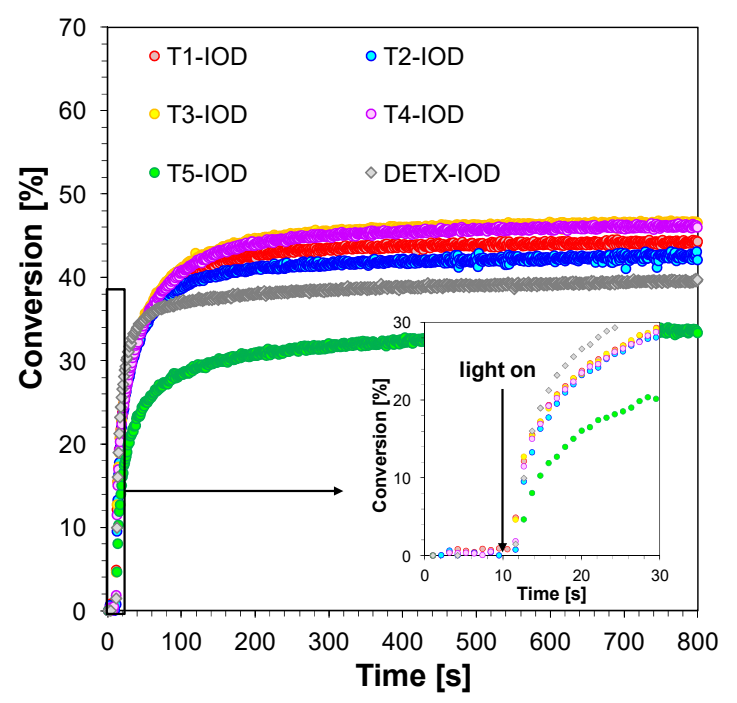

(a)

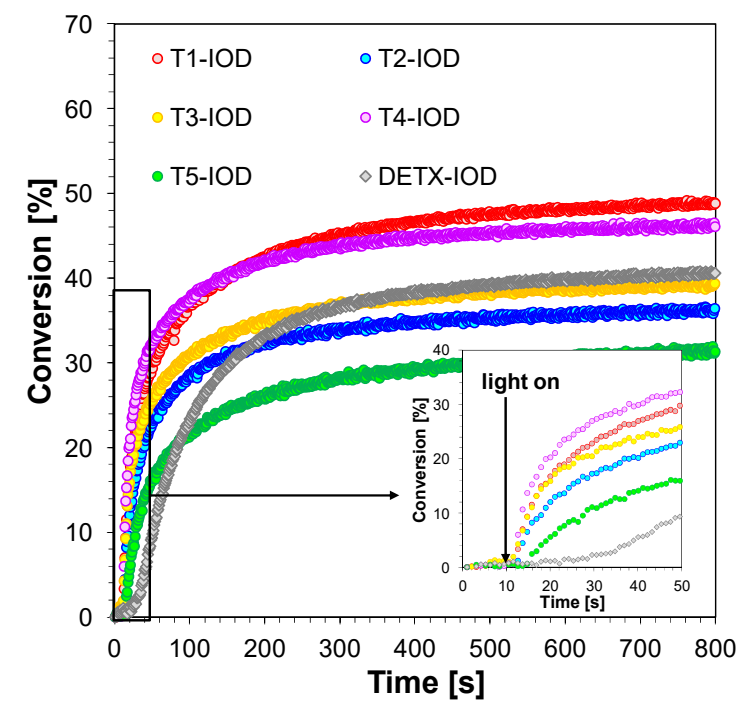

(b)

Figure 3. Photopolymerisation profiles of UVACURE ${ }^{\circledR} 1500$ (epoxy function conversion vs. irradiation time under air in the presence of different photoinitiating systems based on IOD $(1 \% w / w)$ and 2,4-diethyl-thioxanthen-9-one derivatives $(0.2 \% w / w))$ upon exposure to (a) the visible LED@405 nm, (b) the visible LED@420 nm. The irradiation starts at $\mathrm{t}=10 \mathrm{~s}$.

Table 2. Functional group conversions of the epoxy monomer UVACURE ${ }^{\circledR} 1500$ using a photoinitiating systems based on 2,4-diethyl-thioxanthen-9-one derivatives $\left(5.3 \times 10^{-3} \mathrm{~mol} \cdot \mathrm{dm}^{-3}\right.$, $\sim 0.2 \% \mathrm{wt}$.) and bis(4-t-butylphenyl)iodonium hexafluorophosphate (IOD $1 \% w / w$ ) or triarylsulfonium hexafluorophosphate (TAS 2\% w/w) under irradiation LED@405 nm and LED@420 nm.

\begin{tabular}{|c|c|c|c|c|c|c|c|c|}
\hline \multirow{3}{*}{ Sensitizer } & \multicolumn{4}{|c|}{ Photoinitiating System with TAS (2\%) } & \multicolumn{4}{|c|}{ Photoinitiating System with IOD (1\%) } \\
\hline & \multicolumn{2}{|c|}{$\begin{array}{c}405 \mathrm{~nm}, \\
\mathrm{I}_{0}=17.24 \mathrm{~mW} \cdot \mathrm{cm}^{-2}\end{array}$} & \multicolumn{2}{|c|}{$\begin{array}{c}420 \mathrm{~nm}, \\
\mathrm{I}_{0}=14.87 \mathrm{~mW} \cdot \mathrm{cm}^{-2}\end{array}$} & \multicolumn{2}{|c|}{$\begin{array}{c}405 \mathrm{~nm}, \\
\mathrm{I}_{0}=17.24 \mathrm{~mW} \cdot \mathrm{cm}^{-2}\end{array}$} & \multicolumn{2}{|c|}{$\begin{array}{c}420 \mathrm{~nm}, \\
\mathrm{I}_{0}=14.87 \mathrm{~mW} \cdot \mathrm{cm}^{-2}\end{array}$} \\
\hline & $\begin{array}{l}t_{\text {ind }} \\
{[s]}\end{array}$ & $\begin{array}{l}\text { FC } \\
{[\%]}\end{array}$ & $\begin{array}{c}t_{\text {ind }} \\
{[\mathrm{s}]}\end{array}$ & $\begin{array}{l}\text { FC } \\
{[\%]}\end{array}$ & $\begin{array}{c}t_{\text {ind }} \\
{[\mathrm{s}]}\end{array}$ & $\begin{array}{l}\text { FC } \\
{[\%]}\end{array}$ & $\begin{array}{c}t_{\text {ind }} \\
{[s]}\end{array}$ & $\begin{array}{l}\mathrm{FC} \\
{[\%]}\end{array}$ \\
\hline $\mathrm{T} 1$ & 1 & 59 & 1 & 56 & 1 & 44 & 1 & 48 \\
\hline $\mathrm{T} 2$ & 1 & 34 & 6 & 42 & 1 & 42 & 2 & 36 \\
\hline T3 & 1 & 53 & 2 & 51 & 1 & 46 & 1 & 39 \\
\hline T4 & 1 & 36 & 2 & 25 & 1 & 46 & 1 & 46 \\
\hline T5 & 1 & 33 & 14 & 29 & 2 & 33 & 4 & 31 \\
\hline DETX & 1 & 28 & 18 & 15 & 1 & 39 & 17 & 40 \\
\hline
\end{tabular}

FC-final conversion, $t_{\text {ind }}$-induction time. 
Polymerisation performance during cationic polymerisation in the presence of initiating systems with diaryliodonium salt is also satisfactory. Initiating systems based on compounds T1, T2, T3 and T4 are the most efficient under LED with emission at $\lambda_{\max }=405 \mathrm{~nm}$ and superior to the reference DETX/IOD (Figure 3a). Clearly, all investigated compounds are better sensitizers than the reference-2,4-diethylthioxanthen-9-one-upon exposure to LED with emission at $\lambda_{\max }=420 \mathrm{~nm}$, because of the induction time which is observed for the DETX/IOD system (Figure 3b). This result can be attributed to the better absorption properties (higher molar extinction coefficients) of the investigated compounds at $\lambda_{\max }=420 \mathrm{~nm}$ in comparison to DETX. The higher molar extinction coefficients of $\mathrm{T} 2$ and T5 in comparison to DETX at $420 \mathrm{~nm}$ provide a faster start for the photopolymerisation of cycloaliphatic epoxy monomers for systems based on T2 and T5 than for the system with DETX. The final conversion values are summarised in Table 2.

\subsection{Free-Radical Photopolymerisation of Acrylates in Thin Film Laminate}

2.3.1. Performance of 2,4-Diethyl-thioxanthen-9-one Derivatives as Photosensitizers in Bimolecular Photoinitiating Systems for Free-Radical Photopolymerisation

The most commonly used photoinitiator for acrylates and methacrylates is diphenyl-(2,4,6trimethylbenzoyl)phosphine oxide (TPO), which belongs to the group of Type-I photoinitiators, with absorption maxima at $267 \mathrm{~nm}, 298 \mathrm{~nm}$ and $380 \mathrm{~nm}$. This compound is very efficient as an initiator for UV and visible light. Recently, there have been reports on the toxicity of this compound and, as a result, the use of TPO is being withdrawn by the European Union, especially in food and dental applications $[59,60]$. Therefore, there is a need for new photoinitiating systems for free radical polymerisations as alternatives to TPO. Therefore, in order to understand fully the applicability of thioxanthone derivatives as photosensitizers of onium salts, studies were made on the free-radical polymerisation of acrylate monomers (trimethylolpropane triacrylate). Based on the measurements carried out, it was shown that bimolecular photoinitiating systems consisting of 2,4-diethyl-thioxanthen-9-one derivatives and sulphonium salts are able to initiate the polymerisation of trimethylolpropane triacrylate (TMPTA) effectively. The studied systems based on T1, T2, T3, T4 and TAS initiate polymerisation directly after the LED light source with emission at $\lambda_{\max }=405 \mathrm{~nm}$ was turned on. The final conversion values were around $50 \%$. Diphenyl-(2,4,6-trimethylbenzoyl)phosphine oxide exhibits similar behaviour, but reaches a higher degree of conversion around $70 \%$ of the double bond monomer. The combination of DETX with triarylsulphonium hexafluorophosphate (TAS) as an initiating system for TMPTA leads to the final conversion of 52\%-Figure $4 \mathrm{a}$. Based on the obtained results, it was demonstrated that compounds 2,4-diethyl-7-[4-( $N$-phenylanilino)phenyl]thioxanthen-9-one (T1), 2,4-diethyl-7-(9-phenylcarbazol-3-yl)thioxanthen-9-one (T3) and 7-carbazol-9-yl-2,4-diethylthioxanthen-9-one (T4) are more efficient in photoinitiating systems with sulphonium salt than DETX, because polymerisation processes begin faster and the degrees of conversion are higher.

The photoinitiating performance of TPO upon exposure to visible LED at $\lambda_{\max }=420 \mathrm{~nm}$ is slightly less than with LED at $\lambda_{\max }=405 \mathrm{~nm}$. This is due to the absorption properties of the phosphine-based compound. Sensitizers T1, T3 and T4 possess similar photosensitizing properties at $420 \mathrm{~nm}$ because their molar extinction coefficients are higher than the other investigated thioxanthone derivatives. Conversely, compounds 7-(3-carbazol-9-ylphenyl)-2,4-diethyl-thioxanthen-9-one (T2), 7-(4-carbazol-9ylphenyl)-2,4-diethyl-thioxanthen-9-one (T5) and DETX exhibit rather poor photosensitizing efficiency with triarylsulphonium salt under irradiation at $420 \mathrm{~nm}$-Figure $4 \mathrm{~b}$.

The performance of 2,4-diethylthioxanthen-9-one derivatives in two-component photoinitiating systems with diaryliodonium salt (IOD) for acrylate monomer TMPTA is similar, for visible LED sources with emissions both at $405 \mathrm{~nm}$ and $420 \mathrm{~nm}$-Figure 5a,b. The photopolymerisation of acrylate monomers starts directly after turning on the LED at $405 \mathrm{~nm}$ in the presence of all studied photoinitiating systems. This behaviour is also observed for the diphenyl-(2,4,6-trimethylbenzoyl)phosphine oxide (TPO) initiator. The double bond conversion can reach up to $60 \%$ with systems based on iodonium salt with T1, T2 or T3. Although the 7-carbazol-9-yl-2,4-diethyl-thioxanthen-9-one with iodonium 
salt photoinitiating system exhibits lower polymerisation efficiency than the above derivatives, the final acrylate conversion is around $50 \%$. The bimolecular system consisting of 7-(4-carbazol9-ylphenyl)-2,4-diethyl-thioxanthen-9-one (T5) and iodonium salt (IOD) is the least effective with final conversion value of $40 \%$.

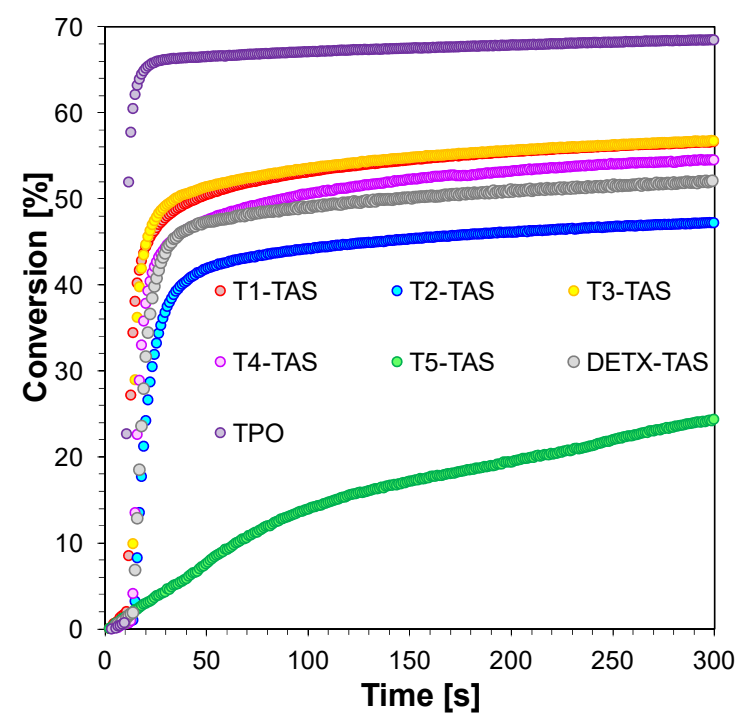

(a)

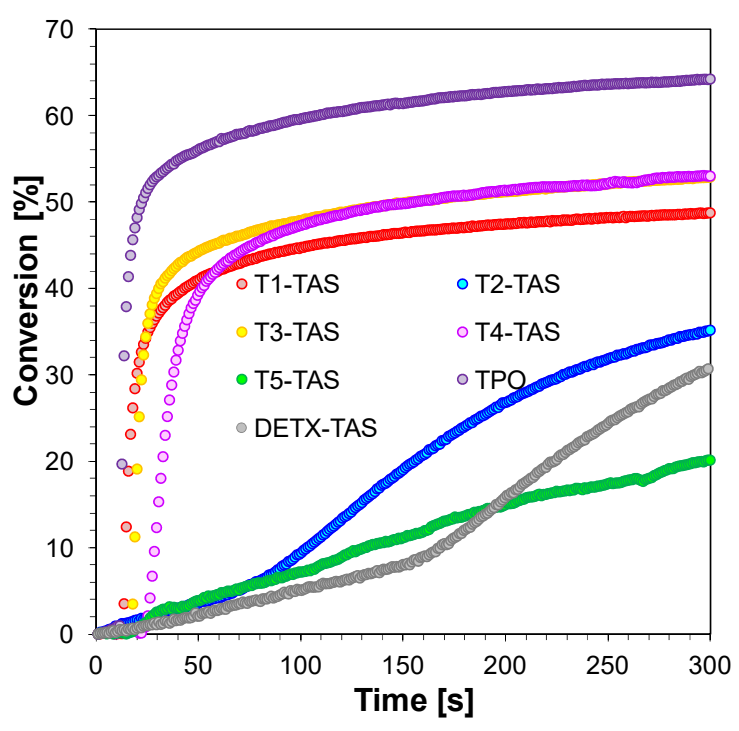

(b)

Figure 4. Polymerisation profiles of trimethylolpropane triacrylate (TMPTA) (acrylate function conversion vs. irradiation time in laminate in the presence of different photoinitiating systems based on TAS $(2 \% w / w)$ and 2,4-diethyl-thioxanthen-9-one derivatives $(0.2 \% w / w)$ upon exposure to (a) the visible LED@405 $\mathrm{nm}(\mathbf{b})$ the visible LED@420 $\mathrm{nm}$. The irradiation starts at $\mathrm{t}=10 \mathrm{~s}$.

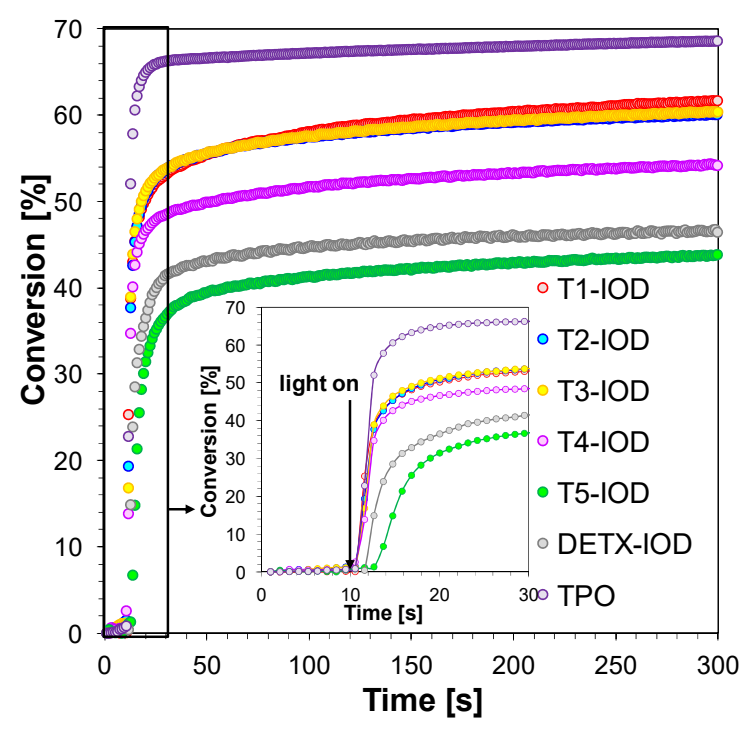

(a)

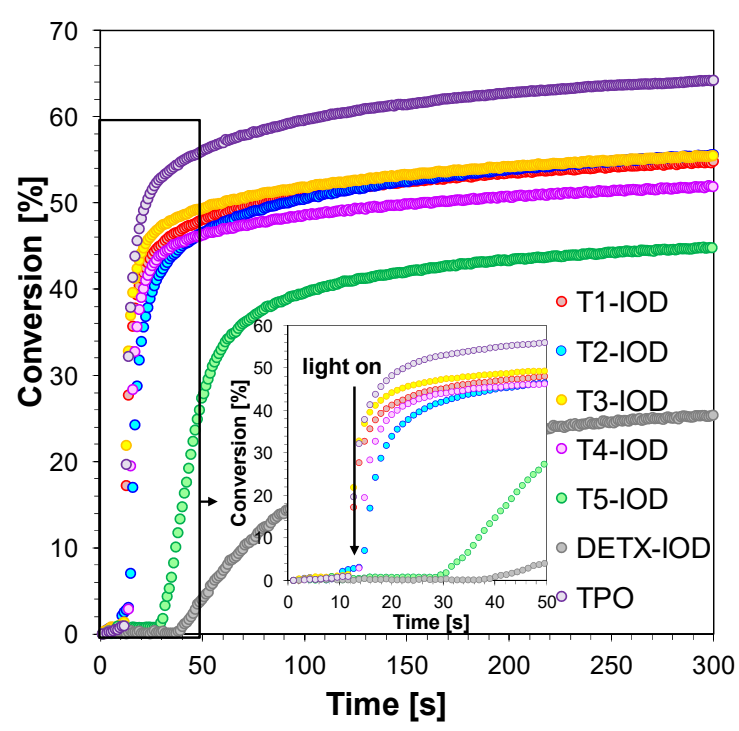

(b)

Figure 5. Polymerisation profiles of TMPTA (acrylate function conversion vs. irradiation time) in laminate in the presence of different photoinitiating systems based on IOD $(1 \% w / w)$ and 2,4-diethyl-thioxanthen-9-one derivatives $(0.2 \% w / w)$ upon exposure to (a) the visible LED@405 $\mathrm{nm}(\mathbf{b})$ to the visible LED@420 nm. The irradiation starts at $\mathrm{t}=10 \mathrm{~s}$.

Compounds T1, T2, T3 and T4 exhibit similar initiating efficiency upon exposure to visible LED at $420 \mathrm{~nm}$, with conversions of 54\%. As previously, the T5/IOD system is characterised by 
the smallest value of final conversion (around 44\%) and longer induction time than the rest of the studied photosensitizers. This is associated with the absorption properties of 7-(4-carbazol-9-ylphenyl)2,4-diethyl-thioxanthen-9-one (T5) and its molar extinction coefficient at $420 \mathrm{~nm}$. The reference system with 2,4-diethyl-thioxanthen-9-one exhibits similar efficiency with previous polymerisations. The DETX/IOD system is more efficient than the system based on compound T5 but less effective than compounds T1-T4 at $405 \mathrm{~nm}$, and the least effective at $420 \mathrm{~nm}$. The final conversion values for acrylate monomer in the presence of bimolecular photoinitiating systems with IOD and TAS are summarised in Table 3.

The experimental results, which are presented and discussed above, show that 2,4-diethylthioxanthen-9-one derivatives are quite efficient in photooxidation processes. An electron is transferred from the excited state of the photosensitizer to the onium salt, bis(4-t-butylphenyl)-iodonium hexafluorophosphate (IOD), as well as to the triarylsulphonium hexafluorophosphate salt (TAS) and enables the initiation reaction. This fact will be described below in the mechanism section.

Table 3. Functional group conversions of acrylate monomer TMPTA using a photoinitiating systems based on 2,4-diethyl-thioxanthen-9-one derivatives $\left(5.3 \times 10^{-3} \mathrm{~mol} \cdot \mathrm{dm}^{-3}, \sim 0.2 \%\right.$ wt.) and bis(4-t-butylphenyl)iodonium hexafluorophosphate (IOD $1 \% w / w$ ) or triarylsulfonium hexafluorophosphate (TAS 2\% w/w) under irradiation LED@405 nm and LED@420 nm.

\begin{tabular}{|c|c|c|c|c|c|c|c|c|}
\hline \multirow{3}{*}{ Sensitizer } & \multicolumn{4}{|c|}{ Photoinitiating System with TAS (2\%) } & \multicolumn{4}{|c|}{ Photoinitiating System with IOD (1\%) } \\
\hline & \multicolumn{2}{|c|}{$\begin{array}{c}405 \mathrm{~nm}, \\
I_{0}=17.24 \mathrm{~mW} \cdot \mathrm{cm}^{-2}\end{array}$} & \multicolumn{2}{|c|}{$\begin{array}{c}420 \mathrm{~nm}, \\
\mathrm{I}_{0}=14.87 \mathrm{~mW} \cdot \mathrm{cm}^{-2}\end{array}$} & \multicolumn{2}{|c|}{$\begin{array}{c}405 \mathrm{~nm}, \\
I_{0}=17.24 \mathrm{~mW} \cdot \mathrm{cm}^{-2}\end{array}$} & \multicolumn{2}{|c|}{$\begin{array}{c}420 \mathrm{~nm}, \\
\mathrm{I}_{0}=14.87 \mathrm{~mW} \cdot \mathrm{cm}^{-2}\end{array}$} \\
\hline & $\begin{array}{l}\mathbf{t}_{\text {ind }} \\
{[\mathrm{s}]}\end{array}$ & $\begin{array}{l}\text { FC } \\
{[\%]}\end{array}$ & $\begin{array}{c}t_{\text {ind }} \\
{[\mathrm{s}]}\end{array}$ & $\begin{array}{l}\text { FC } \\
{[\%]}\end{array}$ & $\begin{array}{l}\mathbf{t}_{\text {ind }} \\
{[\mathrm{s}]}\end{array}$ & $\begin{array}{l}\text { FC } \\
{[\%]}\end{array}$ & $\begin{array}{l}t_{\text {ind }} \\
{[s]}\end{array}$ & $\begin{array}{l}\text { FC } \\
{[\%]}\end{array}$ \\
\hline $\mathrm{T} 1$ & 0 & 56 & 1 & 48 & 0 & 61 & 1 & 54 \\
\hline $\mathrm{T} 2$ & 3 & 47 & 30 & 35 & 0 & 60 & 3 & 55 \\
\hline T3 & 3 & 56 & 6 & 53 & 0 & 60 & 1 & 55 \\
\hline $\mathrm{T} 4$ & 2 & 54 & 14 & 53 & 0 & 54 & 3 & 51 \\
\hline T5 & 3 & 24 & 10 & 20 & 2 & 44 & 19 & 44 \\
\hline DETX & 2 & 52 & 15 & 30 & 1 & 46 & 28 & 25 \\
\hline TPO * & 0 & 68 & 1 & 64 & 0 & 68 & 1 & 64 \\
\hline
\end{tabular}

* One component free-radical photoinitiator, FC-final conversion, $\mathrm{t}_{\text {ind }}$-induction time.

2.3.2. 2,4-Diethyl-thioxanthen-9-one Derivatives as One Component Free-Radical Photoinitiators during Photopolymerisation of Acrylate Monomers

All of the investigated compounds consist of two chromophore parts: thioxanthone and a part containing 4-(diphenylamine)phenyl substituent or moiety with carbazole. In this work, we checked if the 2,4-diethyl-thioxanthen-9-one derivatives would be able to act as one-component initiators without any additives, because amine is incorporated into the structure of each compound.

Free radical polymerisation of acrylate monomer TMPTA was performed in the presence of studied 2,4-diethyl-thioxanthen-9-one derivatives as a one-component type II photoinitiator upon exposure to LED $405 \mathrm{~nm}$ and $420 \mathrm{~nm}$. All of investigated compounds act as one-component free-radical photoinitiator with the exception of 7-(4-carbazol-9-ylphenyl)-2,4-diethyl-thioxanthen9-one (T5)-Figure 6a,b. DETX alone also does not initiate photopolymerisation reactions. Compound in which 2,4-diethyl-thioxanthone is directly linked with carbazole: 7-carbazol-9-yl-2,4-diethylthioxanthen-9-one (T4) exhibit the best photoinitiating activity both under LED@405 nm and LED@420 nm with final conversion values around 50\%. Slightly less photoinitiating ability possess 2,4-diethyl-7-[4-(N-phenylanilino)phenyl]thioxanthen-9-one (T1) and 2,4-diethyl-7-(9-phenylcarbazol3-yl)thioxanthen-9-one (T3). Performance of 7-(3-carbazol-9-ylphenyl)-2,4-diethyl-thioxanthen-9-one (T2) is the weakest as a one-component photoinitiating system.

It should be highlighted that 2,4-diethyl-thioxanthen-9-one derivatives were used in very small concentration $5.3 \times 10^{-3} \mathrm{~mol} \cdot \mathrm{dm}^{-3}(\sim 0.2 \%)$. In the next step, we decided to investigate how a higher concentration of initiator affects the efficiency of initiation. This experiment was carried out for 
one selected initiator $\mathrm{T} 1$, for three different concentrations $0.2 \%, 0.4 \%$ and $0.6 \%$. As can be seen in Figure 7, it turned out that as the initiator concentration increases, the photopolymerisation efficiency is improved (induction time, polymerisation rate and final conversion values are summarized in Table 4). Photopolymerisation starts faster (induction time is shortened) and polymerisation rates are also higher for samples with increased concentration of initiator. It can be concluded that studied 2,4-diethyl-thioxanthen-9-one derivatives T1, T2, T3 and T4 are effective one-component initiators for free radical polymerisation and can be used in very small quantities, but the concentration of photoinitiator guarantees better photopolymerisation efficiency.

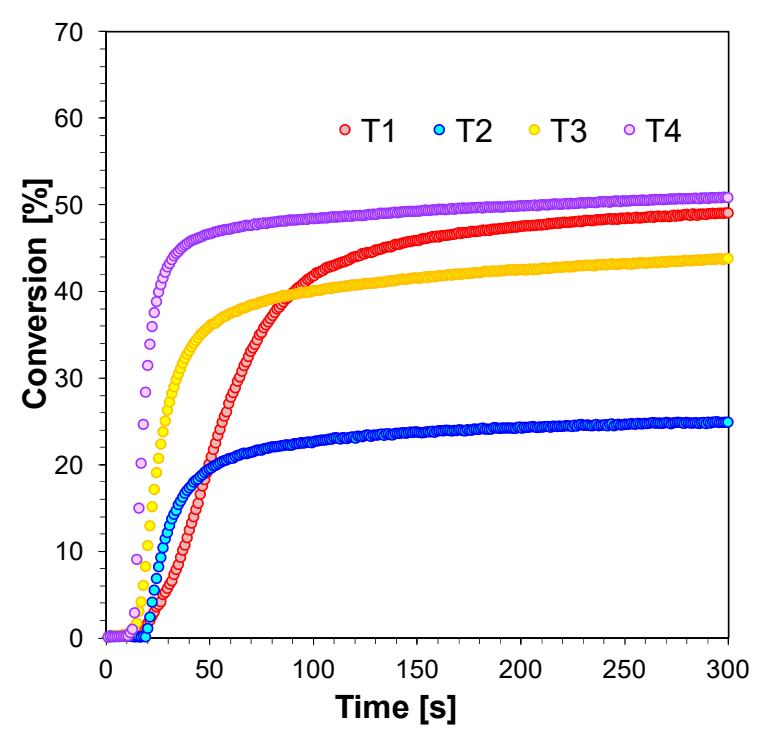

(a)

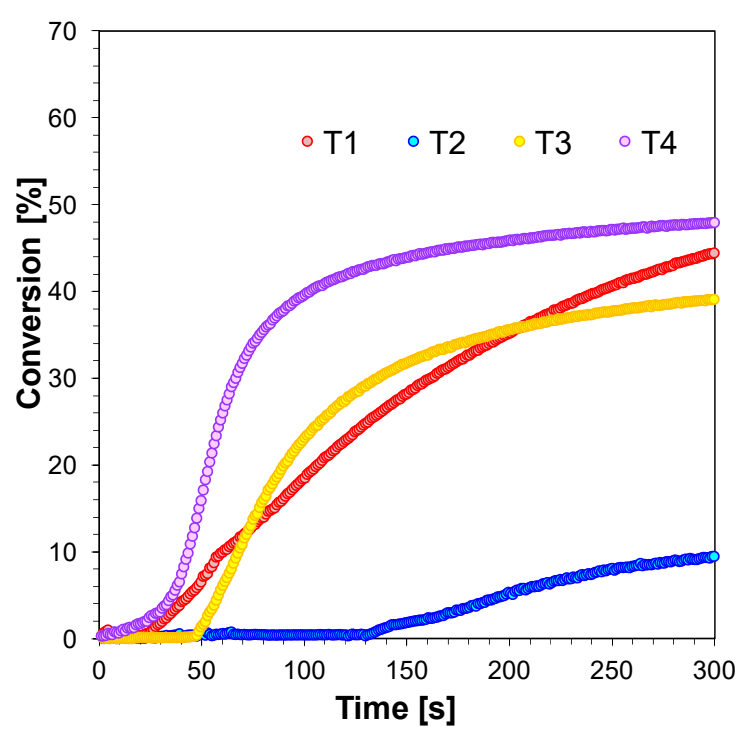

(b)

Figure 6. Polymerisation profiles of TMPTA (acrylate function conversion vs. irradiation time in laminate in the presence 2,4-diethyl-thioxanthen-9-one derivatives $(0.2 \% w / w)$ upon exposure to (a) the visible LED@405 nm (b) the visible LED@420 nm. The irradiation starts at $\mathrm{t}=10 \mathrm{~s}$.

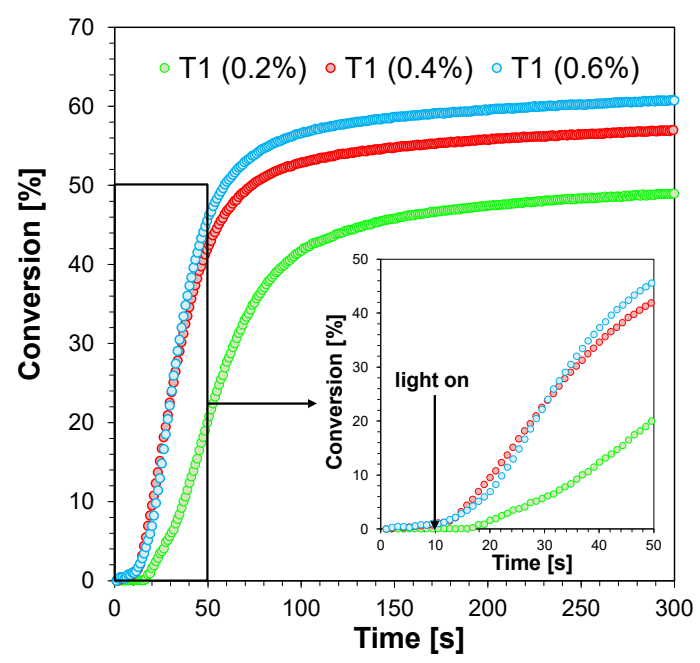

Figure 7. Polymerisation profiles of TMPTA (acrylate function conversion vs. irradiation time) upon exposure to the visible LED@405 nm in laminate in the presence of 2,4-diethyl-7-[4-( $N$ phenylanilino)phenyl]thioxanthen-9-one (T1) $(0.2 \%, 0.4 \%$ and $0.6 \% w / w)$. The irradiation starts at $\mathrm{t}=10 \mathrm{~s}$. 
Table 4. Functional group conversions of acrylate monomer TMPTA using different concentration of a photoinitiator T1 under LED $405 \mathrm{~nm}$.

\begin{tabular}{ccc}
\hline Concentration of Photoinitiator T1 & $\begin{array}{c}\mathbf{t}_{\text {ind }} \\
{[\mathbf{s}]}\end{array}$ & FC [\%] \\
\hline $5.3 \times 10^{-3} \mathrm{~mol} \cdot \mathrm{dm}^{-3}(0.2 \%)$ & 9 & 49 \\
$10.6 \times 10^{-3} \mathrm{~mol} \cdot \mathrm{dm}^{-3}(0.4 \%)$ & 3 & 57 \\
$15.9 \times 10^{-3} \mathrm{~mol} \cdot \mathrm{dm}^{-3}(0.6 \%)$ & 3 & 60 \\
\hline$t_{\text {ind }}[\mathrm{s}]$-induction time, FC [\%]—final conversion.
\end{tabular}

2.3.3. 2,4-Diethyl-thioxanthen-9-one Derivatives as Type II Photoinitiators during Photopolymerisation of Acrylate Monomers

As thioxanthone derivatives belong to Type II photoinitiators and were originally used in combination with hydrogen donors (amine), the investigated compounds were also applied as Type II photoinitiators in conjunction with amines: ethyl 4-(dimethylamino)benzoate (EDB) and $\mathrm{N}$-phenylglycine (NPG). The interaction of thioxanthone derivatives with an amine is connected with the electron transfer process. As can be seen in Figure $8 \mathrm{a}-\mathrm{d}$, free radical polymerisation occurs in the presence of bimolecular photoinitiating systems based on 2,4-diethyl-thioxanthen-9-one derivatives and ethyl 4-(dimethylamino)benzoate (EDB) or N-phenylglycine (NPG). Photoinitiating efficiency for compounds T1, T2, T3 and T4 is comparable with a final conversion of around $50 \%$ in the presence of both EDB and NPG. Moreover, independently of the used light source (visible LEDs at $405 \mathrm{~nm}$ or $420 \mathrm{~nm}$ ), the results are similar. All final conversion values are summarised in Table 5. The reference systems, DETX/EDB and DETX/NPG, are characterised by slightly lower photoinitiating efficiency in comparison to compounds T1-T4. Only compound 7-(4-carbazol-9-ylphenyl)-2,4-diethyl-thioxanthen-9-one (T5) is a weaker photosensitizer, which is in agreement with the behaviour of photoinitiating systems with iodonium and sulphonium salts.

Table 5. Functional group conversions of acrylate monomer TMPTA using a photoinitiating systems based on 2,4-diethyl-thioxanthen-9-one derivatives alone $\left(5.3 \times 10^{-3} \mathrm{~mol} \cdot \mathrm{dm}^{-3}, \sim 0.2 \% \mathrm{wt}\right.$. $)$ or with amines: ethyl 4-(dimethylamino)benzoate (EDB 1.5\% w/w) or N-phenylglycine (NPG $1.17 \% w / w)$ under irradiation LED@405 nm and LED@420 nm.

\begin{tabular}{|c|c|c|c|c|c|c|}
\hline \multirow{4}{*}{$\begin{array}{l}\text { Photo- } \\
\text { Sensitizer }\end{array}$} & \multicolumn{6}{|c|}{ Conversion of the Acrylate Monomer TMPTA [\%] } \\
\hline & \multirow{2}{*}{\multicolumn{2}{|c|}{$\begin{array}{c}\text { One-Component } \\
\text { Photoinitiatng System }\end{array}$}} & \multicolumn{4}{|c|}{ Two-Component Photoinitiating System } \\
\hline & & & \multicolumn{2}{|c|}{ with NPG } & \multicolumn{2}{|c|}{ with NPG } \\
\hline & $\begin{array}{l}@ 405 \mathrm{~nm} \\
\mathrm{I}_{0}=17.24 \\
\mathrm{~mW} \cdot \mathrm{cm}^{-2}\end{array}$ & $\begin{array}{l}@ 420 \mathrm{~nm}, \\
\mathrm{I}_{0}=14.87 \\
\mathrm{~mW} \cdot \mathrm{cm}^{-2}\end{array}$ & $\begin{array}{c}@ 405 \mathrm{~nm} \\
\mathrm{I}_{0}=17.24 \\
\mathrm{~mW} \cdot \mathrm{cm}^{-2}\end{array}$ & $\begin{array}{l}@ 420 \mathrm{~nm}, \\
\mathrm{I}_{0}=14.87 \\
\mathrm{~mW} \cdot \mathrm{cm}^{-2}\end{array}$ & $\begin{array}{c}@ 405 \mathrm{~nm} \\
\mathrm{I}_{0}=17.24 \\
\mathrm{~mW} \cdot \mathrm{cm}^{-2}\end{array}$ & $\begin{array}{l}@ 420 \mathrm{~nm} \\
\mathrm{I}_{0}=14.87 \\
\mathrm{~mW} \cdot \mathrm{cm}^{-2}\end{array}$ \\
\hline $\mathrm{T} 1$ & 49 & 44 & 53 & 50 & 57 & 53 \\
\hline $\mathrm{T} 2$ & 25 & 10 & 50 & 47 & 51 & 56 \\
\hline T3 & 43 & 39 & 47 & 47 & 56 & 52 \\
\hline $\mathrm{T} 4$ & 51 & 47 & 48 & 48 & 53 & 53 \\
\hline T5 & - & - & 30 & 27 & 42 & 40 \\
\hline DETX & - & - & 45 & 42 & 50 & 51 \\
\hline
\end{tabular}




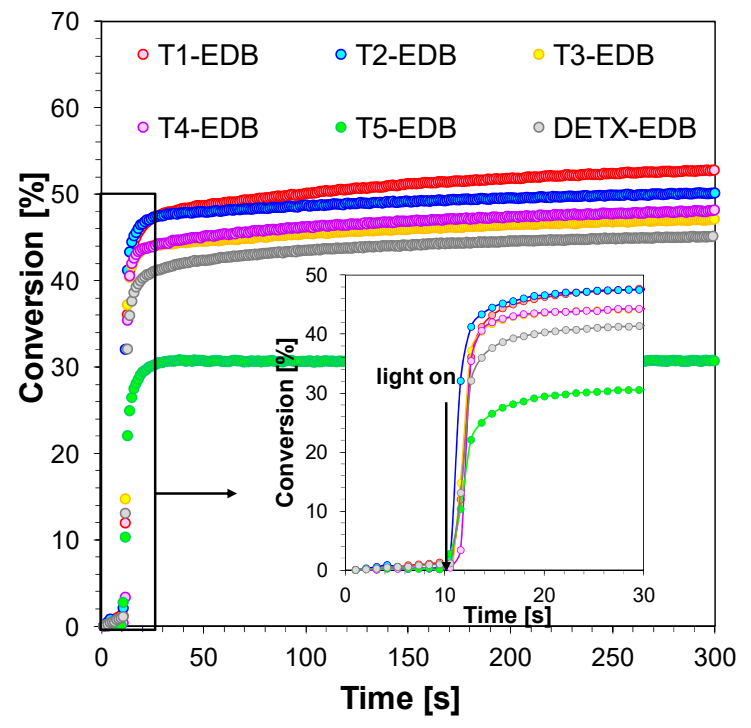

(a)

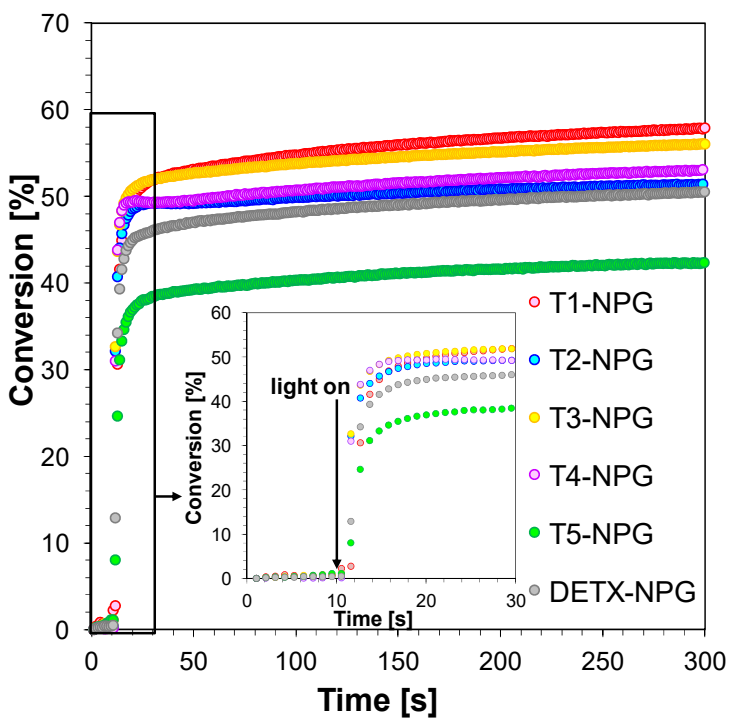

(c)

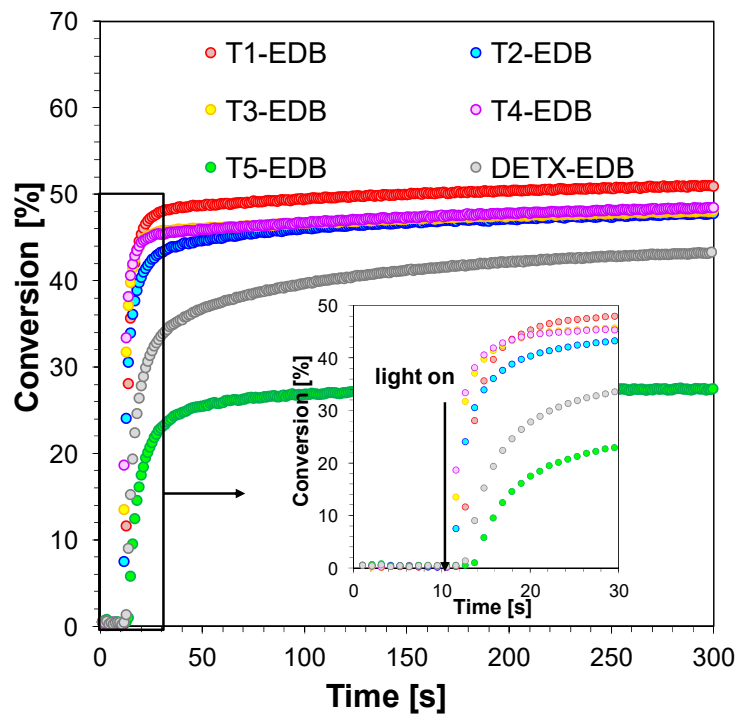

(b)

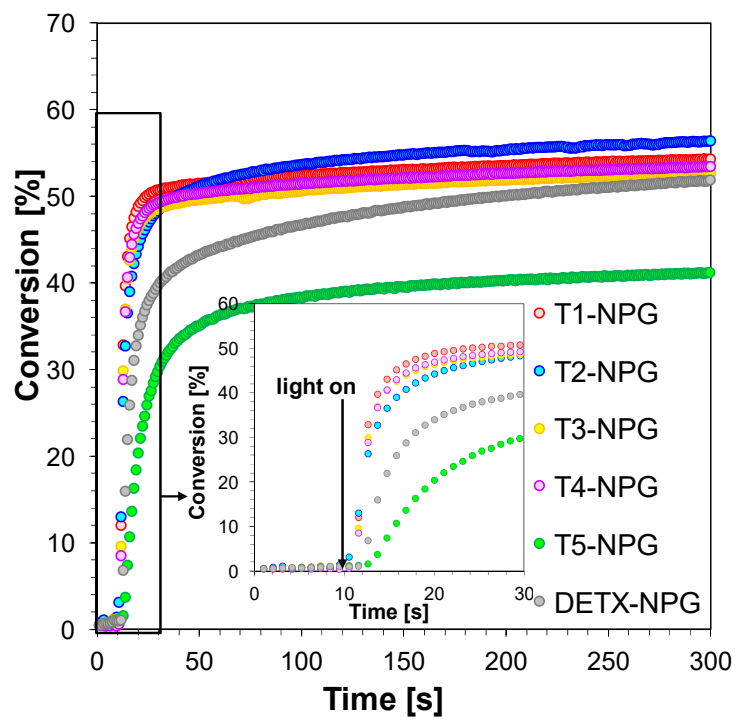

(d)

Figure 8. Polymerisation profiles of TMPTA (acrylate function conversion vs. irradiation time) in laminate in the presence of different photoinitiating systems based on EDB $(1.5 \% w / w)$ and 2,4-diethyl-thioxanthen-9-one derivatives $(0.2 \% w / w)$ upon exposure to (a) the visible LED@405 nm, (b) to the visible LED@420 nm. Polymerisation profiles of TMPTA (acrylate function conversion vs. irradiation time) in laminate in the presence of different photoinitiating systems based on NPG $(1.17 \% w / w)$ and 2,4-diethyl-thioxanthen-9-one derivatives $(0.2 \% w / w)$ upon exposure to (c) the visible LED@405 nm, (d) the visible LED@405 nm. The irradiation starts at $\mathrm{t}=10 \mathrm{~s}$.

\subsubsection{Three-Component Photoinitiating Systems-Photocatalyst Behaviour of T1}

Derivatives of 2,4-diethyl-thioxanthen-9-one with (4-diphenylamine)phenyl substituent (T1) were selected as an example to study photocatalytic properties and performance in three-component photoinitiating systems for the polymerisation of acrylate monomer (TMPTA). All polymerisation processes were carried out upon exposure to LED at $420 \mathrm{~nm}$, as a safe light source from the visible range. A lower light intensity was used than for previous measurements to track kinetics and observe slight differences in the behaviour of the investigated photoinitiating systems. First of all, the three-molecular photoinitiating system (T1/EDB/IOD) consisted of a sensitizer, 
2,4-diethyl-7-[4-(N-phenylanilino)phenyl]thioxanthen-9-one (T1), ethyl 4-(dimethylamino)benzoate (EDB) as the co-initiator and diphenyliodonium salt (IOD). It was compared with bimolecular systems T1/IOD and T1/EDB. As can be seen from Figure 9a, the performance based on the final conversion of three-component system T1/EDB/IOD (final conversion $=49 \%$ ) is better than that of the two-component systems: T1/IOD and T1/EDB (final conversions 39\% and $44 \%$ respectively). In the next step, systems with $\mathrm{N}$-phenylglycine and iodonium salt were investigated. According to Figure $9 \mathrm{~b}$, three-component photoinitiating system T1/NPG/IOD (conversion $=57 \%$ ) is superior to T1/NPG (conversion $=47 \%$ ) and $\mathrm{T} 1 / \mathrm{IOD}$ (conversion $=39 \%$ ). In both cases there is a trend: T1/amine/IOD $>\mathrm{T} 1 / \mathrm{amine}>\mathrm{T} 1 / \mathrm{IOD}$.

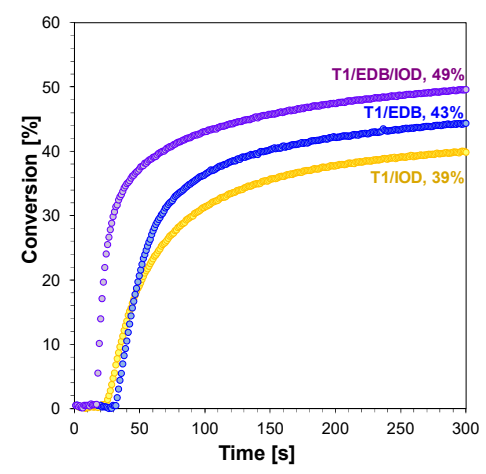

(a)

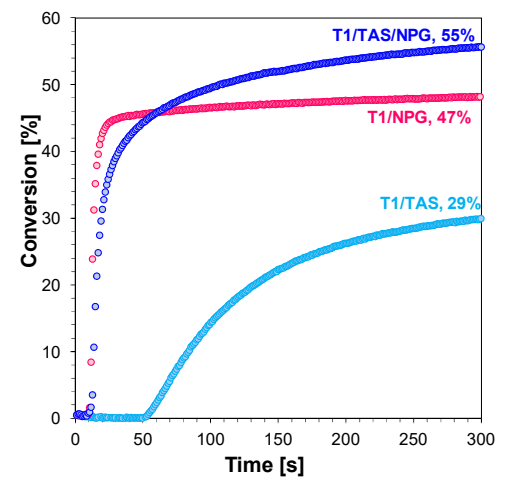

(d)

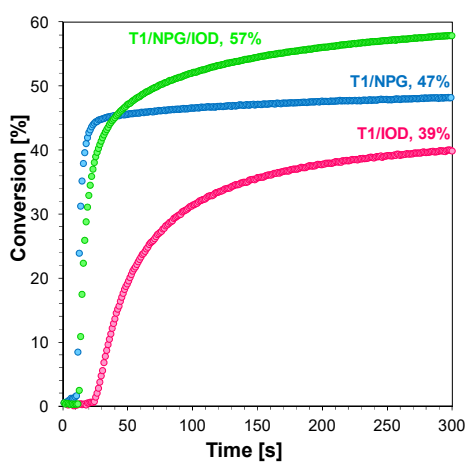

(b)

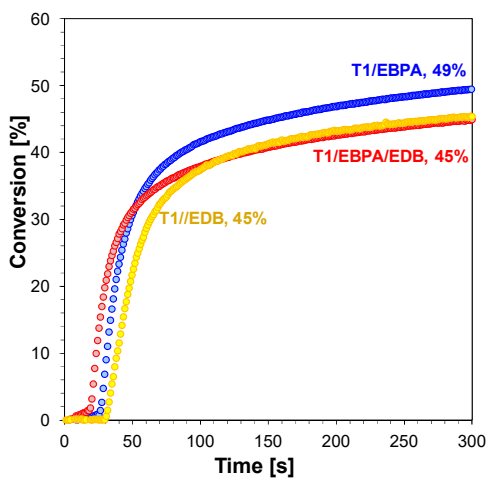

(e)

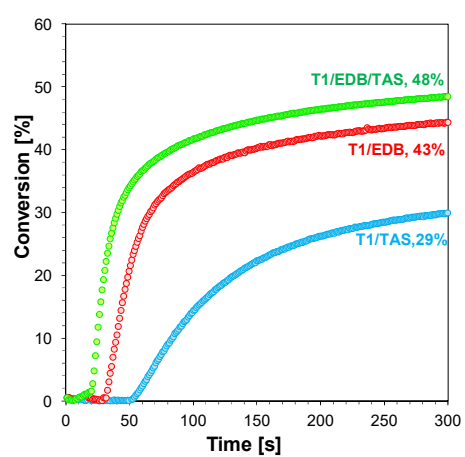

(c)

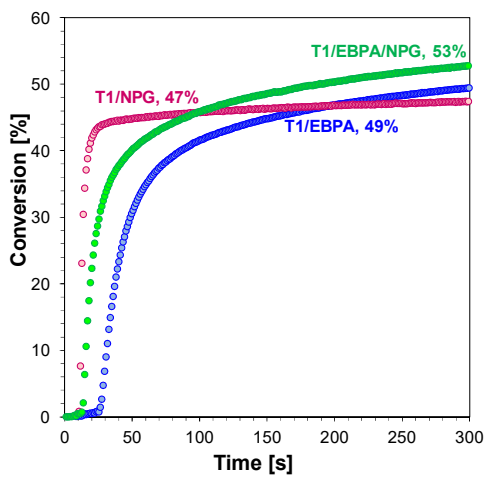

(f)

Figure 9. Polymerisation profiles of TMPTA (acrylate function conversion vs. irradiation time) upon exposure to the visible LED@420 $\mathrm{nm}\left(0.60 \mathrm{~mW} \cdot \mathrm{cm}^{-2}\right)$ in laminate in the presence of different photoinitiating systems (a) T1/EDB/IOD, T1/EDB, T1/IOD, (b) T1/NPG/IOD, T1/NPG, T1/IOD, (c) T1/EDB/TAS, T1/EDB, T1/TAS, (d) T1/TAS/NPG, T1/NPG, T1/TAS, (e) T1/EBPA, T1/EBPA/EDB, T1/EDB, (f) T1/EBPA/NPG, T1/NPG, T1/EBPA (Concentrations of photoinitiating systems components: T1 $\sim .2 \%$, EDB 1.5\%, IOD 1\%, NPG 1.17\%, TAS 2\%, EBPA 1.5\%). The irradiation starts at $\mathrm{t}=10 \mathrm{~s}$.

Photoinitiating systems containing compound T1, amine and sulphonium salt were also examined. Figure $9 \mathrm{c}$ presents the polymerisation profiles obtained after polymerisation processes with systems T1/EDB/TAS/, T1/ EDB and T1/TAS. In this case, the three-component system is also more efficient than the bimolecular combination of sensitizer with amine or sensitizer with sulphonium salt. Similar performance is observed for systems based on 2,4-diethyl-7-[4-(Nphenylanilino)phenyl]thioxanthen-9-one (T1) with triarylsulphonium salt and $N$-phenylglycine (Figure 9d). Photoinitiation efficiency of systems based on T1/NPG (conversion $=47 \%$ ) and T1/TAS (conversion $=29 \%$ ) is less than that of the corresponding three-component system: T1/TAS/NPG (conversion $=55 \%$ ). The performance of systems with triarylsulphonium salt and amines is in the following order: T1/amine/TAS $>$ T1/amine $>$ T1/TAS. 
The next type of photoinitiating system for free radical polymerisation investigated in this work is the combination of 2,4-diethyl-7-[4-( $N$-phenylanilino)phenyl]thioxanthen-9-one (T1) with alkyl halide EBPA (ethyl $\alpha$-bromophenylacetate) and/or amine. The results are depicted in Figure 9e,f. According to the systems with EDB and alkyl halide, the interaction of T1 with EBPA (conversion $=49 \%$ ) is much more favourable than interaction with amine EDB (conversion $=45 \%$ ). A different situation is observed for systems with NPG and EBPA. Three-component system T1/NPG/EBPA is superior to two-component photoinitiating systems: T1/EDB and T1/EBPA-Figure 9f. Final conversion values these systems are summarised in Table 6.

Table 6. Functional group conversions of the acrylate monomer TMPTA using different two- and three-component photoinitiating systems after $300 \mathrm{~s}$ of irradiation LED@420 $\mathrm{nm}\left(\mathrm{I}_{0}=0.60 \mathrm{~mW} \cdot \mathrm{cm}^{-2}\right)$, concentration of initiating systems, $\mathrm{d} \alpha / \mathrm{dt}$ and induction time.

\begin{tabular}{cccc}
\hline Photoinitiating System & Concentration [\%] & $\mathbf{t}_{\text {ind }}$ [s] & Final Conversion [\%] \\
\hline T1/EDB/IOD & $0.2 \% / 1.5 \% / 1.0 \%$ & 7 & 49 \\
T1/EDB & $0.2 \% / 1.5 \%$ & 21 & 44 \\
T1/IOD & $0.2 \% / 1.0 \%$ & 14 & 39 \\
T1/NPG & $0.2 \% / 1.17 \%$ & 0 & 47 \\
T1/NPG/IOD & $0.2 \% / 1.17 \% / 1.0 \%$ & 2 & 57 \\
T1/EDB/TAS & $0.2 \% / 1.5 \% / 2.0 \%$ & 10 & 48 \\
T1/TAS & $0.2 \% / 2.0 \%$ & 41 & 29 \\
T1/TAS/NPG & $0.2 \% / 2.0 \% / 1.17 \%$ & 1 & 55 \\
T1/EBPA & $0.2 \% / 1.5 \%$ & 16 & 49 \\
T1/EBPA/EDB & $0.2 \% / 1.5 \% / 1.5 \%$ & 9 & 44 \\
T1/EBPA/NPG & $0.2 \% / 1.5 \% / 1.17 \%$ & 3 & 53 \\
\hline
\end{tabular}

2.4. Photochemical Mechanism-Dual Photochemical Behaviour of 2,4-Diethyl-thioxanthen-9-one Derivatives during Photopolymerisation by Photoreduction and Photooxidation Processes

\subsubsection{2,4-Diethyl-thioxanthen-9-one Derivatives as Electron Donors in Two-Component Systems}

Photosensitization of onium salt occurs by an electron transfer process. An electron is transferred from the excited photosensitizer (electron donor) to the onium salt (electron acceptor). As a result, a photoredox reaction takes place in which the photosensitizer is oxidised, while the onium salt is reduced. This process is regulated by the redox potentials of the photosensitizers and onium salts. The feasibility of the photosensitization process can be determined by the Rehm-Weller equation. It is possible to calculate the energy change in the electron transfer reaction $\left(\Delta \mathrm{G}_{\mathrm{et}}\right)$. The more negative $\Delta \mathrm{G}_{\mathrm{et}}$ is, the more feasible the possibility of the electron transfer. The free energy $\left(\Delta \mathrm{G}_{\mathrm{et}}\right)$ values for all studied bimolecular photoinitiating systems were estimated using the Rehm-Weller equation [61]. In order to determine $\Delta \mathrm{G}_{\mathrm{et}}$, which accompanies the electron transfer in the studied two-component initiation systems, the energy of singlet state $\left(\mathrm{E}_{00}\right)$ was determined based on measurements of excitation and emission spectra (example for $\mathrm{T} 1$ in Figure 10c, the rest of the figures are found in Supplementary Materials). The oxidation and reduction potential of 2,4-diethyl-thioxanthen-9-one derivatives were determined by cyclic voltammetry (examples of cyclic voltammograms for compound 2,4-diethyl-7-[4-(N-phenylanilino)phenyl]thioxanthen-9-one (T1) are depicted in Figure 10a,b, cyclic voltammograms for other compounds are in Supplementary Materials). The values of oxidation potentials are listed in Table 7 and the values of reduction potentials are in Table 8. Oxidation potentials are in the range of $1063 \mathrm{mV}$ for 2,4-diethyl-7-[4-( $N$-phenylanilino)phenyl]thioxanthen-9-one (T1) to $1353 \mathrm{mV}$ for 7-(4-carbazol-9-ylphenyl)-2,4-diethyl-thioxanthen-9-one (T5). It is worth mentioning that all investigated compounds are characterised by lower values of oxidation potential in comparison to the basic compound DETX. The calculated values of $\left(\Delta \mathrm{G}_{e t}\right)$ for the studied photoinitiating systems oscillate in the range between -1.09 and $-0.91 \mathrm{eV}$ for the singlet excited state of thioxanthone derivatives with diphenyliodonium salt (IOD). These values are accordingly higher considering the 
energy of the triplet state. Triarylsulphonium salt is characterised by lower values of reduction potential. As a result of energy change calculations, $\Delta \mathrm{G}_{\mathrm{et}}$ are higher than for iodonium salt but still negative (from $-0.91 \mathrm{eV}$ to $-0.74 \mathrm{eV}$ ). Moreover, $\Delta \mathrm{G}_{\mathrm{et}}$ values both for photosensitizer/IOD or photosensitizer/TAS for 2,4-diethyl-thioxanthen-9-one derivatives are more favourable than $\Delta \mathrm{G}_{\mathrm{et}}$ for DETX/IOD and DETX/TAS. According to the cyclic voltammograms presented in Figure 10a, compound 2,4-diethyl-7-[4-( $N$-phenylanilino)phenyl]thioxanthen-9-one (T1) is characterised by reversible oxidation and reduction peaks. Other analysed compounds (cyclic voltammograms in Supporting Information) show "partial reversibility". Reversibility is crucial for the photocatalytic behaviour of photosensitizers. Therefore, compound T1 was selected as an example to study its photoredox properties and performance in three-component photoinitiating systems. Compound T1 2,4-diethyl-7-[4-(N-phenylanilino)phenyl]thioxanthen-9-one was used in bimolecular photoinitiating system with EBPA (ethyl $\alpha$-bromophenylacetate). Reduction potential for EBPA is -1.26 V [62], calculated $\Delta \mathrm{G}_{\mathrm{et}}$ value for electron transfer between T1 and EBPA is also favourable, $\Delta \mathrm{G}_{\mathrm{et}}=-0.44 \mathrm{eV}$ and $\Delta \mathrm{G}_{\mathrm{et}}=-0.20 \mathrm{eV}$ for singlet and triplet excited state, respectively.

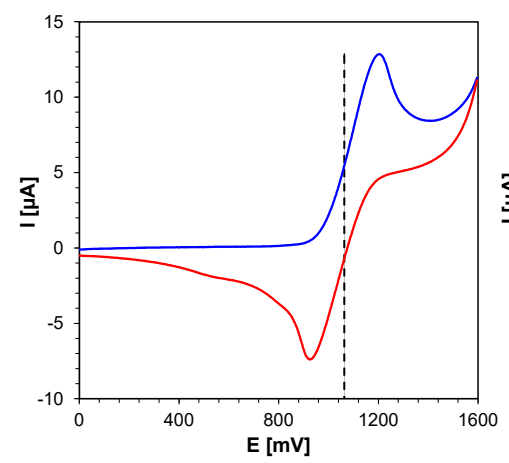

(a)

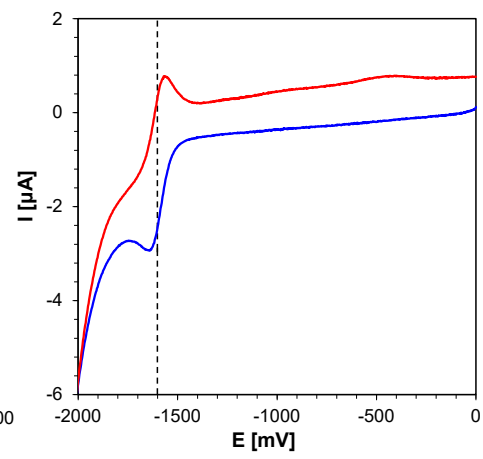

(b)

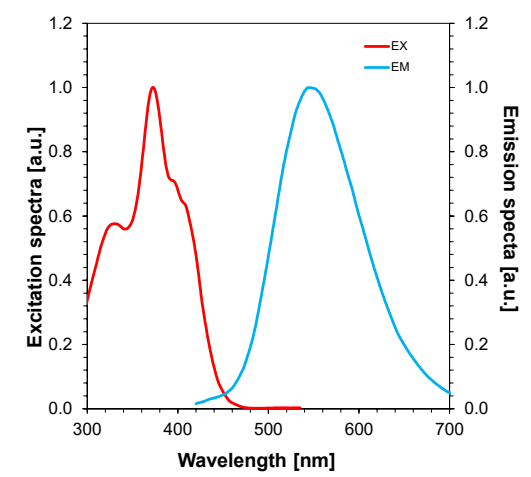

(c)

Figure 10. Cyclic voltammogram of the (a) $\mathrm{T} 1$ oxidation, (b) $\mathrm{T} 1$ reduction in $\mathrm{CHCl}_{3}$ (with $0.1 \mathrm{M}$ solution of tetrabutylammonium hexafluorophosphate electrolyte and $\mathrm{Ag} / \mathrm{AgCl}$ as reference electrode, scan rate $100 \mathrm{mV} / \mathrm{s}$ ). (c) Normalized excitation and emission spectra for $\mathrm{T} 1$ in $\mathrm{CHCl}_{3}$.

Table 7. Electrochemical and thermodynamic properties of sensitizers and their interaction with iodonium salt (IOD) and sulfonium salt (TAS).

\begin{tabular}{|c|c|c|c|c|c|c|c|}
\hline LOT & $\begin{array}{c}\mathrm{E}_{\mathrm{Ox}}[\mathrm{mV}] \\
\text { vs. } \\
\mathrm{Ag} / \mathrm{AgCl}\end{array}$ & $\mathrm{E}_{\mathrm{S} 1}[\mathrm{eV}]$ & $\mathrm{E}_{\mathrm{T} 1}[\mathrm{eV}]$ & $\begin{array}{l}\Delta \mathrm{G}_{\mathrm{etS1}} \mathrm{vs} . \\
\mathrm{IOD}[\mathrm{eV}]\end{array}$ & $\begin{array}{l}\Delta \mathrm{G}_{\text {etT1 }} \mathrm{vs} . \\
\mathrm{IOD}[\mathrm{eV}]\end{array}$ & $\begin{array}{l}\Delta \mathrm{G}_{\mathrm{etS1}} \mathrm{vs.} \\
\text { TAS }[\mathrm{eV}]\end{array}$ & $\begin{array}{l}\Delta \mathrm{G}_{\text {etT1 }} \text { vs. } \\
\text { TAS }[\mathrm{eV}]\end{array}$ \\
\hline $\mathrm{T} 1$ & 1063 & 2.76 & 2.52 & -1.06 & -0.82 & -0.88 & -0.64 \\
\hline $\mathrm{T} 2$ & 1319 & 3.03 & 2.61 & -1.07 & -0.65 & -0.90 & -0.48 \\
\hline $\mathrm{T} 3$ & 1182 & 2.91 & 2.56 & -1.09 & -0.74 & -0.91 & -0.56 \\
\hline $\mathrm{T} 4$ & 1347 & 2.90 & 2.50 & -0.91 & -0.51 & -0.74 & -0.34 \\
\hline T5 & 1353 & 3.00 & 2.59 & -1.01 & -0.60 & -0.83 & -0.42 \\
\hline DETX & 1675 & 3.00 & 2.64 & -0.69 & -0.33 & -0.51 & -0.10 \\
\hline
\end{tabular}

$\mathrm{E}_{\mathrm{S} 1}$-singlet state energy of sensitizer determined based on absorption and emission. $\mathrm{E}_{\mathrm{T} 1}$ - triplet state energy calculated from molecular orbital calculations (uB3LYP/6-31G* level of theory). $\Delta \mathrm{G}_{\mathrm{et}}$ calculated from the equation: $\Delta G_{\text {et }}=F\left[E_{o x}\left(\frac{D}{D^{\bullet+}}\right)-E_{\text {red }}\left(\frac{\mathrm{A}^{\bullet-}}{A}\right)\right]-E_{00}-\left(\frac{N_{\mathrm{A}} \mathrm{e}^{2}}{4 \pi \varepsilon_{0} \varepsilon_{\mathrm{ra}}}\right), \mathrm{E}_{\mathrm{ox}}\left(\mathrm{D} / \mathrm{D}^{\bullet+}\right)$ - the electrochemically determined oxidation potential of the sensitizer. $\mathrm{E}_{\text {red }}\left(\mathrm{A}^{\bullet-} / \mathrm{A}\right)$ - the electrochemically determined reduction potential of the electron acceptor, for the diaryliodonium salt: $\mathrm{E}_{\text {red IOD }}=0.68 \mathrm{~V}$ vs. SCE $[63,64],\left(\mathrm{E}_{\text {red IOD }}=-0.64 \mathrm{~V}\right.$ vs. $\left.\mathrm{Ag} / \mathrm{AgCl}\right)$, for triarulsulfonium salt: $\mathrm{E}_{\text {red } \mathrm{TAS}}=-0.814 \mathrm{~V}$ vs. $\mathrm{Ag} / \mathrm{AgCl}$-determined in this work. 
Table 8. Electrochemical and thermodynamic properties of sensitizers and their interaction with amines EDB and NPG.

\begin{tabular}{|c|c|c|c|c|c|c|c|}
\hline LOT & $\begin{array}{c}\mathrm{E}_{\text {red }}[\mathrm{mV}] \\
\text { vs. } \\
\mathrm{Ag} / \mathrm{AgCl}\end{array}$ & $\mathrm{E}_{\mathrm{S} 1}[\mathrm{eV}]$ & $\mathrm{E}_{\mathrm{T} 1}[\mathrm{eV}]$ & $\begin{array}{l}\Delta \mathrm{G}_{\mathrm{etS1}} \mathrm{vs.} \\
\mathrm{EDB}[\mathrm{eV}]\end{array}$ & $\begin{array}{l}\Delta \mathrm{G}_{\text {etT1 }} \text { vs. } \\
\text { EDB }[\mathrm{eV}]\end{array}$ & $\begin{array}{l}\Delta \mathrm{G}_{\text {etS1 }} \text { vs. } \\
\text { NPG }[\mathrm{eV}]\end{array}$ & $\begin{array}{l}\Delta \mathrm{G}_{\text {etT1 }} \mathrm{vs.} \\
\text { NPG }[\mathrm{eV}]\end{array}$ \\
\hline $\mathrm{T} 1$ & -1602 & 2.76 & 2.52 & -0.07 & 0.17 & -0.03 & 0.21 \\
\hline T2 & -1591 & 3.03 & 2.61 & -0.35 & 0.07 & -0.31 & 0.11 \\
\hline T3 & -1625 & 2.91 & 2.56 & -0.20 & 0.15 & -0.16 & 0.20 \\
\hline $\mathrm{T} 4$ & -1528 & 2.90 & 2.50 & -0.28 & 0.12 & -0.24 & 0.16 \\
\hline T5 & - & 3.00 & 2.59 & - & - & - & - \\
\hline DETX & -1770 & 3.00 & 2.64 & -0.14 & 0.22 & -0.10 & 0.26 \\
\hline
\end{tabular}

2.4.2. 2,4-Diethyl-thioxanthen-9-one Derivatives as Electron Acceptors in Two-Component Systems with EDB or NPG

The reduction potentials of 2,4-diethyl-thioxanthen-9-one derivatives have values from -1528 $\mathrm{mV}$ for 7-carbazol-9-yl-2,4-diethyl-thioxanthen-9-one (T4) to -1625 mV for 2,4-diethyl-7-(9phenylcarbazol-3-yl)thioxanthen-9-one (T3). There was a problem with the registration of the reduction signal for compound 7-(4-carbazol-9-ylphenyl)-2,4-diethyl-thioxanthen-9-one (T5); therefore, this compound was not taken into consideration during further calculations. Experimental results show that 2,4-diethyl-thioxanthen-9-one derivatives are efficient in photoreduction processes involving the electron transfer process from the amine to the excited state of the thioxanthone chromophore. According to the $\Delta \mathrm{G}_{\text {et }}$ values summarised in Table 8 , the electron transfer from EDB or NPG to thioxanthone derivatives is feasible and thermodynamically favourable for all investigated compounds from the singlet excited state.

\subsection{D Printing Experiments (Laser Writing)}

Three-dimensional printing experiments upon laser diode irradiation at $405 \mathrm{~nm}$ were conducted in air using different photoinitiating systems based on 2,4-diethyl-7-[4-(N-phenylanilino)phenyl] thioxanthen-9-one (T1) in TMPTA and in a TMPTA/UVACURE ${ }^{\circledR} 1500$ blend. High photosensitivity of the formulations with photoinitiating systems based on thioxanthone derivative T1 allows for an efficient photopolymerisation in the irradiated area. In this experiment, samples were obtained with high spatial resolution in very short time (less than one minute). The fact that no oxygen inhibition was observed in samples of the TMPTA monomer alone is important, as it makes them useful in coatings and visible light-induced additive manufacturing. The obtained samples were analysed microscopically. The patterns are shown in Figures 11-15.

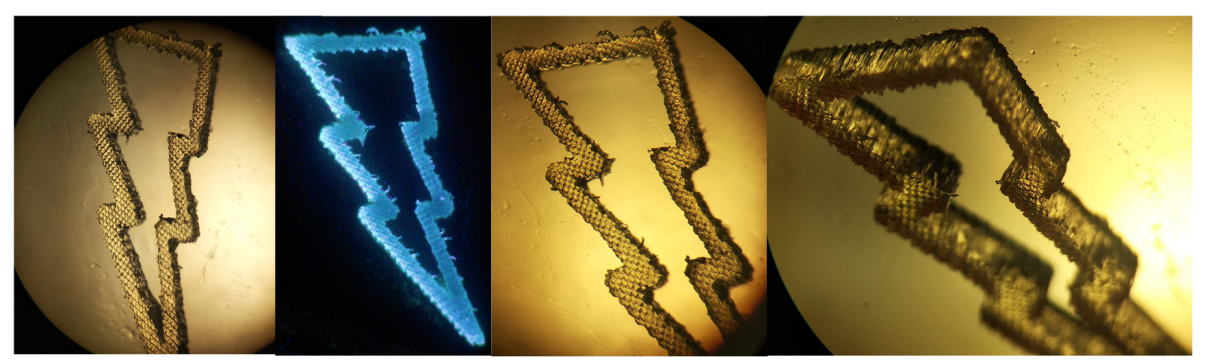

Figure 11. The pattern obtained after the 3D printing experiment based on formulation with $\mathrm{T} 1$ $(0.07 \% w / w)$ and TMPTA. 


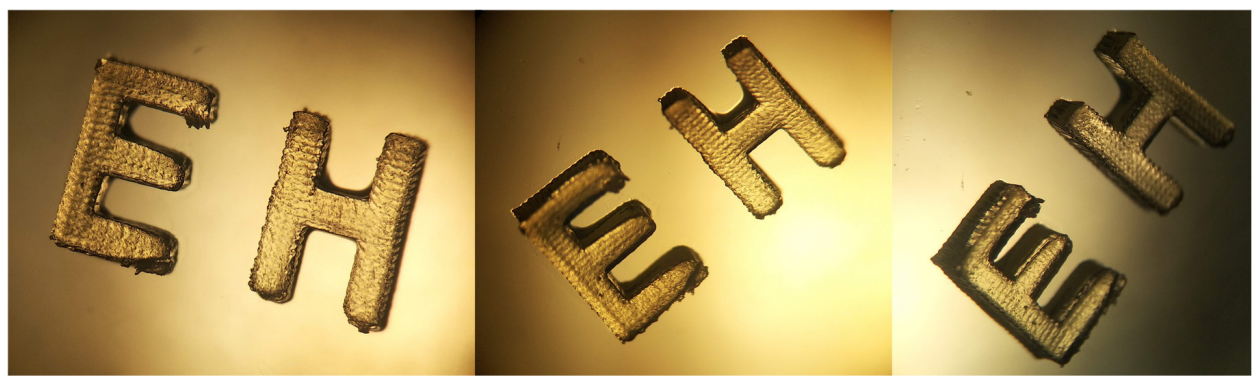

Figure 12. The pattern obtained after the 3D printing experiment based on formulation with $\mathrm{T} 1$ (0.07\% wt.)/IOD (0.33\% wt.) and TMPTA.

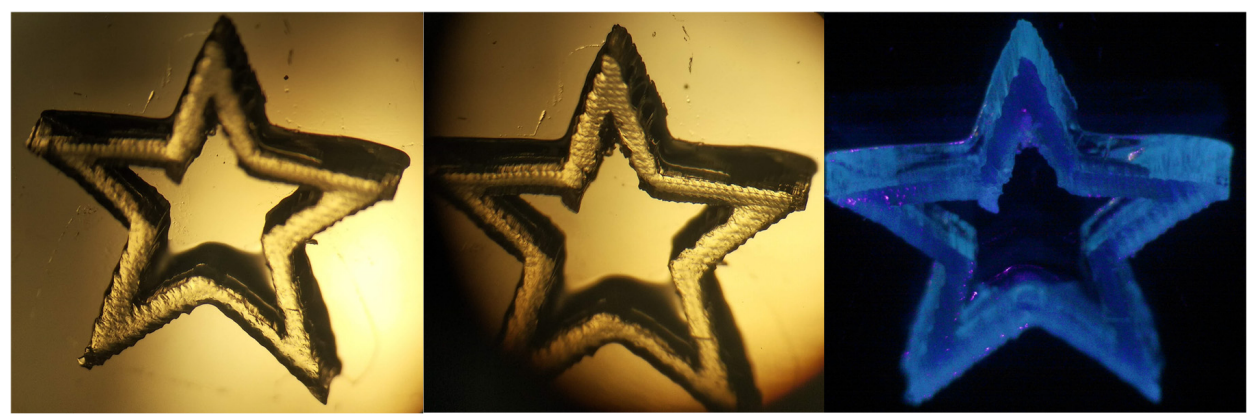

Figure 13. The pattern obtained after the 3D printing experiment based on formulation with $\mathrm{T} 1$ $(0.07 \%$ wt. $) / \mathrm{EDB}(0.5 \% \mathrm{wt}$.$) and TMPTA.$

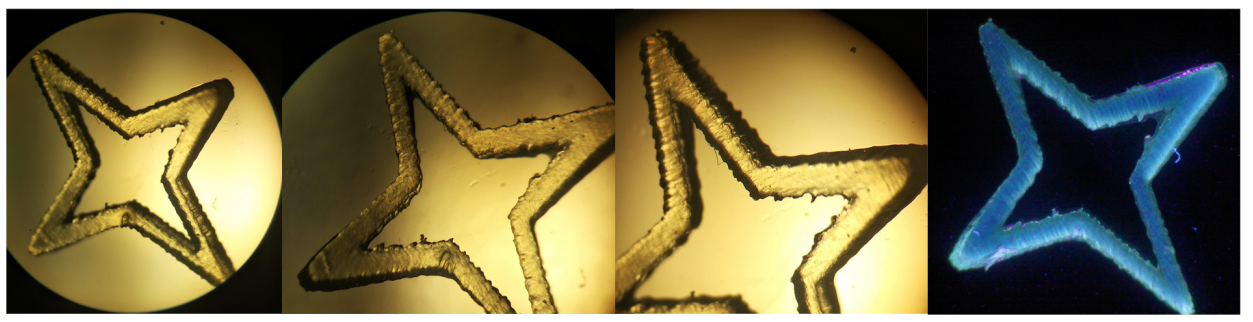

Figure 14. The pattern obtained after the 3D printing experiment based on formulation with $\mathrm{T} 1$ $(0.07 \%$ wt. $) / \mathrm{EDB}(0.5 \% \mathrm{wt}.) / \mathrm{IOD}(0.33 \% \mathrm{wt}$.) and TMPTA.

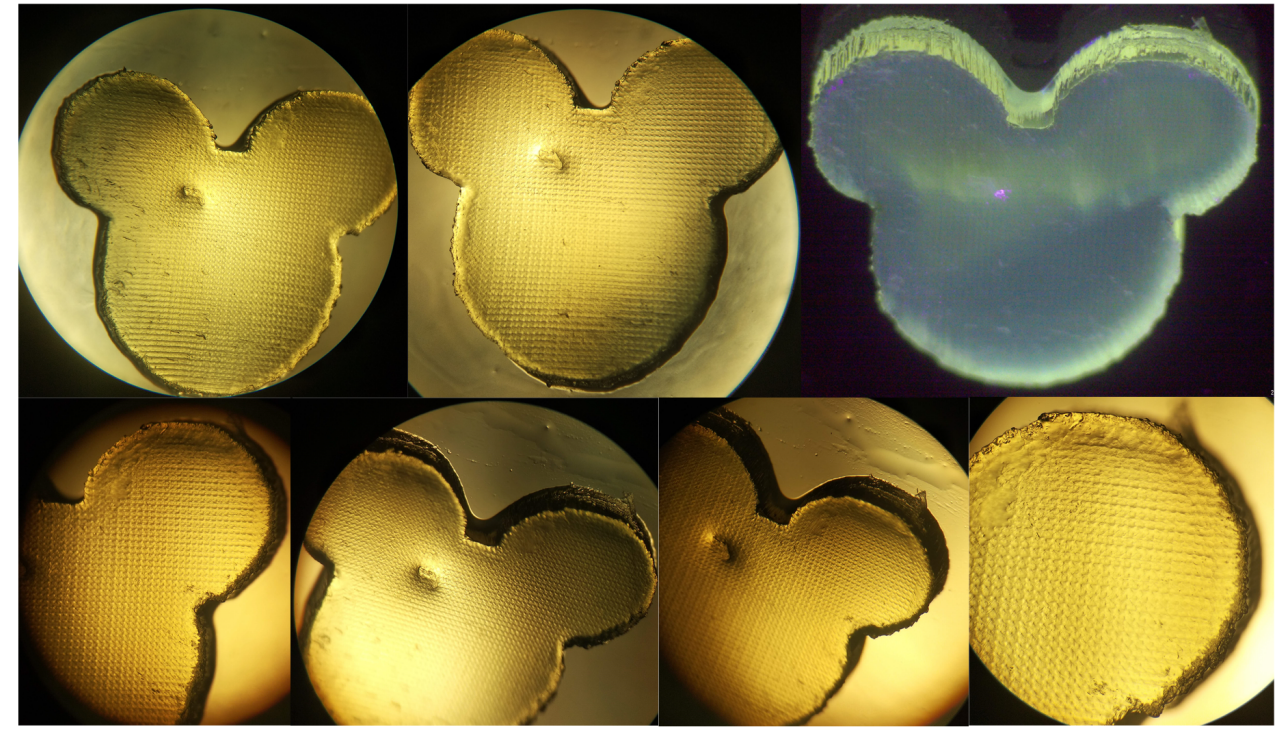

Figure 15. The pattern obtained after the 3D printing experiment based on formulation with $\mathrm{T} 1(0.07 \%$ wt.)/IOD (0.33\% wt.) and TMPTA/UVACURE ${ }^{\circledR} 1500(1: 1)$. 


\section{Materials and Methods}

\subsection{Materials}

The series of 2,4-diethylthioxanthen-9-one derivatives were investigated as a components of photoinitiating systems: 2,4-diethyl-7-[4-( $N$-phenylanilino)phenyl]thioxanthen-9-one (T1), 7-(3-carbazol-9ylphenyl)-2,4-diethylthioxanthen-9-one (T2), 2,4-diethyl-7-(9-phenylcarbazol-3-yl)thioxanthen-9-one (T3), 7-carbazol-9-yl-2,4diethyl-thioxanthen-9-one (T4), 7-(4-carbazol-9-ylphenyl)-2,4-diethylthioxanthen9-one (T5). Details of synthesis and physicochemical data of the 2,4-diethylthioxanthen-9-one derivatives are given in the Supplementary Materials. The structures of these compounds are shown in Scheme 2.

All monomers and other chemical compounds (Scheme 3) were used with the highest available purity. 3,4-epoxycyclohexylmethyl 3,4-epoxycyclohexanecarboxylate (UVACURE ${ }^{\circledR} 1500$, from Allnex, Darmstadt, Germany) were applied as a model cycloaliphatic epoxide monomer for the compositions cured by cationic photopolymerisation. Bis(4-t-butylphenyl)-iodonium hexafluorophosphate (IOD-SpeedCure 938, from Lambson Ltd., Wetherby, UK) and triarylsulfonium hexafluorophosphate salts (TAS, from Sigma Aldrich, Darmstadt, Germany 50\% in propylene carbonate) were used as initiators. Ethyl 4-(dimethylamino)benzoate (EDB, from Sigma Aldrich, Darmstadt, Germany) and N-phenylglycine (NPG from Alfa Aesar, Ward Hill, MA, USA) were used as amines and ethyl $\alpha$-bromophenylacetate (EBPA from Sigma Aldrich, Darmstadt, Germany) was used as an alkyl halide. Diphenyl(2,4,6-trimethylbenzoyl)phosphine oxide (SpeedCure TPO from Lambson Ltd., Wetherby, UK) was used as a free-radical initiator. Trimethylopropane triacrylate (TMPTA, from Sigma Aldrich, Darmstadt, Germany) was employed as acrylate monomer for the compositions polymerized by a free-radical mechanism. 2,4-diethylthioxanthen-9-one (SpeedCure DETX, from Lambson Ltd., Wetherby, UK) was used as a reference photosensitizer.

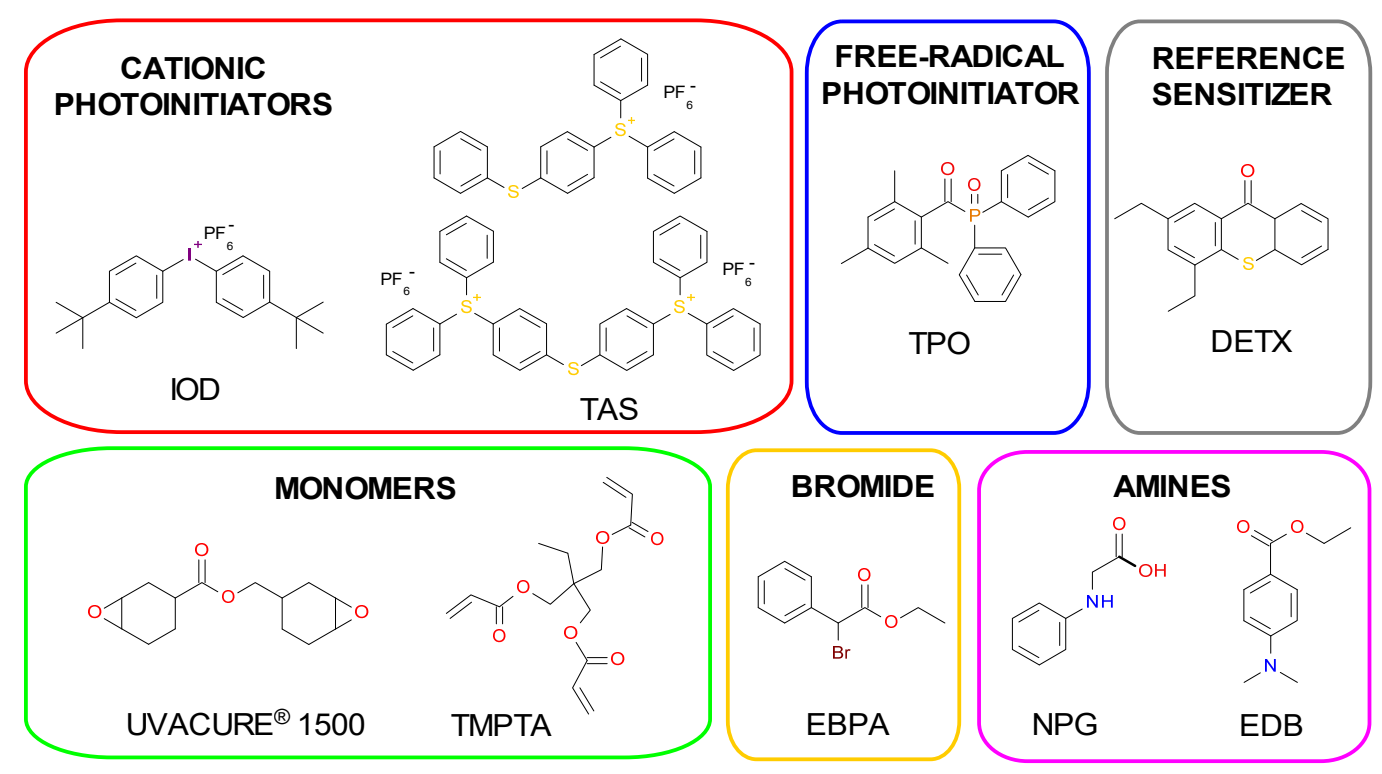

Scheme 3. Monomers and other chemicals.

\subsection{UV-Visible Absorption, Excitation and Emission Spectra}

The absorption spectra were recorded using Silver Nova spectrometer (StellarNet, Inc., Tampa, FL, USA) in combination with a broadband tungsten-deuterium UV-Vis light source and a quartz cuvette with $1.0 \mathrm{~cm}$ optical path at $25^{\circ} \mathrm{C}$. The absorbance data were converted into extinction coefficients and expressed in classical units $\left[\mathrm{dm}^{3} \cdot \mathrm{mol}^{-1} \cdot \mathrm{cm}^{-1}\right]$.

Fluorescence emission and excitation spectra were recorded with Fluoromax ${ }^{\circledR}-4 \mathrm{P}$ (from Horiba, Kyoto, Japan) spectrofluorometer at varied excitation wavelengths in the range of 200-800 nm. 


\subsection{Electrochemical Characteristics Determination of Oxidation Potentials}

The oxidation potentials ( $\mathrm{E}_{\mathrm{ox}} \mathrm{vs} . \mathrm{Ag} / \mathrm{AgCl}$ ) of the studied derivatives of 2,4-diethylthioxanthen9-one were measured in acetonitrile (in chloroform for compound T1) by cyclic voltammetry with tetrabutylammonium hexafluorophosphate (from Sigma Aldrich, Darmstadt, Germany) (0.1 M) as a supporting electrolyte (Electrochemical Analyzer M161 and the Electrode Stand M164, from MTM-ANKO, Cracow, Poland). The working electrode was a platinum disk and, as a reference electrode silver chloride electrode- $\mathrm{Ag} / \mathrm{AgCl}$ was used, measurements were performed with a scan rate of $0.1 \mathrm{~V} / \mathrm{s}$; ferrocene was used as a standard and the potentials were determined from half peak potentials. The Gibbs free energy change $\Delta \mathrm{G}_{\mathrm{et}}$ was calculated from the classical Equation (1) [61]:

$$
\Delta \mathrm{G}_{\mathrm{et}}=\mathrm{F}\left[\mathrm{E}_{\mathrm{ox}}\left(\mathrm{D} / \mathrm{D}^{\bullet+}\right)-\mathrm{E}_{\mathrm{red}}\left(\mathrm{A}^{\bullet-} / \mathrm{A}\right)\right]-\mathrm{E}_{00}-\left(\frac{\mathrm{N}_{\mathrm{A}} \mathrm{e}^{2}}{4 \pi \varepsilon_{0} \varepsilon_{\mathrm{r}} \mathrm{a}}\right)
$$

where: $F$ is the Faraday constant $\left(F=96,485.33289(59) C \cdot \mathrm{mol}^{-1}\right), E_{o x}\left(D / D^{\bullet+}\right)$-oxidation potential of electron donor, $\mathrm{E}_{\mathrm{red}}\left(\mathrm{A}^{\bullet-} / \mathrm{A}\right)$-reduction potential of electron acceptor, $\mathrm{E}_{00}$ - excited state energy, $\mathrm{N}_{\mathrm{A}}$-Avogadro number, e-electron charge, $\varepsilon_{0}$-dielectric permittivity of vacuum, $\varepsilon_{\mathrm{r}}$-dielectric constant of the solvent, a - effective distance between the radical cation $\left(\mathrm{D}^{\bullet+}\right)$ and radical anion $\left(\mathrm{A}^{\bullet-}\right)$ within an ion pair.

The last term in Equation (1) which represents electrostatic interaction energy between the ionic species formed upon the electron transfer, is usually small and becomes practically equal to zero in polar solvents, where the radical ions pairs are dissociated, or in the case of electron transfer between an ion and an unchanged molecule, where no new ion pairs are generated.

\subsection{Computational Procedure}

The energy gap between the first triplet energy $\left(\mathrm{T}_{1}\right)$ and ground state energy $\left(\mathrm{S}_{0}\right)$ was calculating using the Gaussian 09 package. The optimization of $S_{0}$ and $T_{1}$ states was carried out for for all studied compounds. Next, optimization of molecules in the ground state and first triplet excited state was performed using the density functional theory (DFT) method at a B3LYP/6-31G (d, p) level of theory. Energy gap was calculated as the difference of the total energy of the molecule in the first triplet excited state $\left(\mathrm{E}_{\mathrm{T} 1}\right)$ and the total energy of the molecule in the ground state $\left(\mathrm{E}_{\mathrm{S} 0}\right)$. The frontier molecular orbitals properties were analyzed and visualized using GaussView 5.0 software.

\subsection{Photopolymerisation Processes}

Multicomponent photoinitiating systems consisted of onium salts (iodonium salt-IOD or triarylsulfonium salt-TAS) or amine (EDB or NPG) or $\alpha$-bromophenylacetate (EBPA) and 2,4-diethylthioxanthen-9-one derivatives were used for photopolymerisation reactions. The formulations for real-time FT-IR measurements were prepared by dissolution of the onium salts or amine or bromide and each photosensitizer in the appropriate monomer. Concentration of onium salt were equal $1 \%$ for IOD, and $2 \%$ for TAS (because TAS was used as a solution $50 \%$ in propylene carbonate) by weight, concentration of amines was equal $9.0 \times 10^{-2} \mathrm{~mol} \cdot \mathrm{dm}^{-3}(\sim 1.5 \%$ for $\mathrm{EDB}, \sim 1.17 \%$ for NPG). Concentration of studied thioxanthone derivatives as photosensitizers was equal $5.3 \times 10^{-3} \mathrm{~mol} \cdot \mathrm{dm}^{-3}(\sim 0.2 \%)$. Concentration of $\alpha$-bromophenylacetate (EBPA) was $7.0 \times 10^{-2}$ mol. $\mathrm{dm}^{-3}(\sim 1.5 \%)$ and concentration of TPO was $1 \%$.

For monitoring the conversion degree of the monomers during the photopolymerization processes, the real-time FT-IR spectrometer was used (FTIR-i10 NICOLET ${ }^{\text {TM }}$ from Thermo Scientific Waltham, MA, USA) equipped with a horizontal attachment. The light source LED diodes (from Thorlabs Inc., Newton, NJ, USA) coupled with a variable intensity controller (DC2200 regulated power supply also from Thorlabs Inc., Newton, NJ, USA) and fiber optic that allowed for the direction of the light onto the sample on horizontal attachment (Scheme 4). The fiber optic was mounted directly above the place 
for sample at horizontal attachment at height of $2.1 \mathrm{~cm}$. Light was turn on manually on a controller, $10 \mathrm{~s}$ after the start of spectral registration.

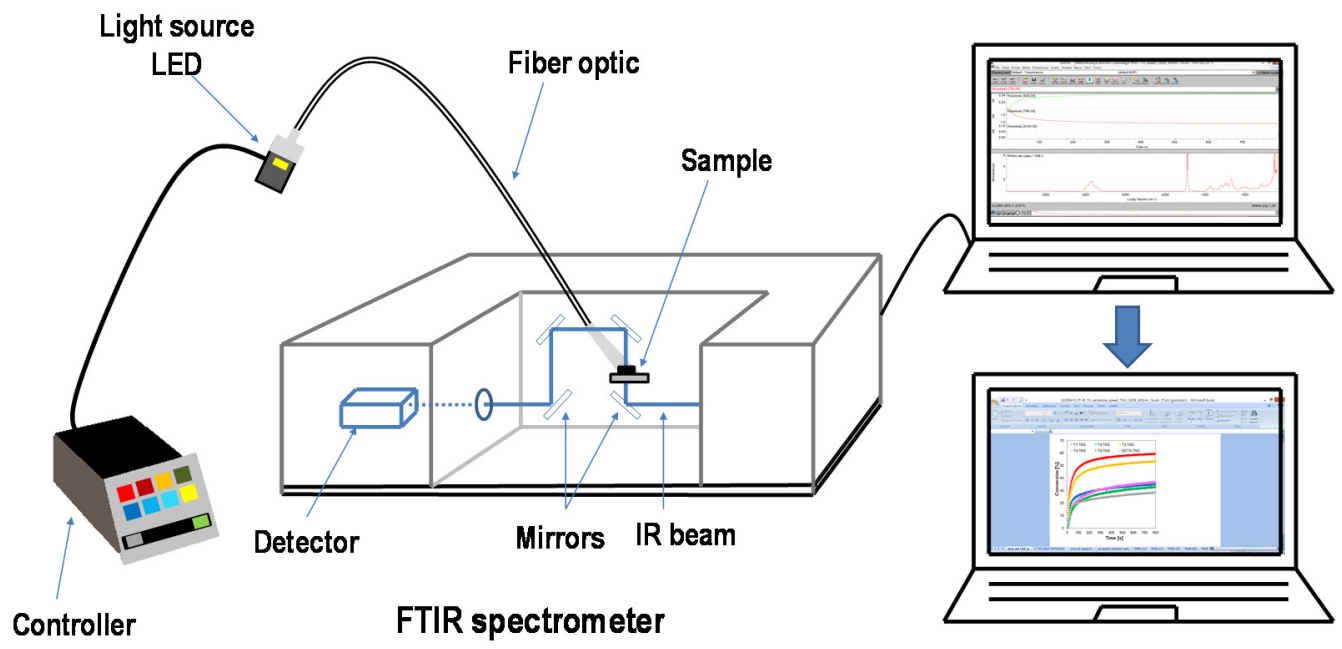

Scheme 4. FT-IR spectrometer was used equipped with a horizontal attachment coupled with a variable intensity controller and fiber optic that allowed for the direction of the light onto the sample.

The bond conversion was calculated using the following equation (Equation (2)), based on the decrease in the absorption area band ratio (Figure 16) before and after light curing:

$$
\text { Conversion } \%=\left[1-\mathrm{A}_{\mathrm{t}} / \mathrm{A}_{0}\right] \times 100 \%
$$

where $A_{t}$ is the area of the characteristic absorbance peak depending on the type of monomer and type of photopolymerisation process and $\mathrm{A}_{0}$ is the initial area of the same characteristic absorbance peak depending on the type of monomer and type of photopolymerisation process.

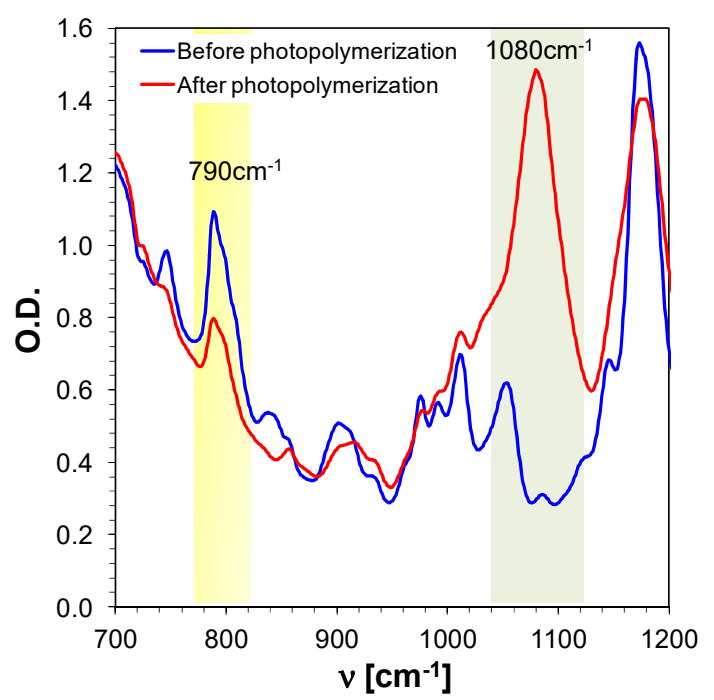

Figure 16. FT-IR spectra before and after polymerization of epoxy monomer UVACURE ${ }^{\circledR} 1500$ under LED@405 nm in the presence of sulphonium salt TAS $(2 \% w / w)$ and sensitizer T1 $(0.2 \% w / w)$.

Kinetic analysis of all spectral data was performed using a spectral difference approach (integration method of the Thermo Scientific OMNIC software-OMNIC ${ }^{\mathrm{TM}}$ software). The bounds for the integration of each sample were determined by visual analysis. The integration method was applied to the spectra using the macro provided by Thermo Scientific to ensure that all spectra for a sample were analyzed using the same integration parameters. 


\subsubsection{Cationic Photopolymerisation of Epoxy Monomer UVACURE ${ }^{\circledR} 1500$}

The photocurable compositions ( $25 \mu \mathrm{m}$ thick) were deposited on a $\mathrm{BaF}_{2}$ pellet under air. The evolution of the epoxy group content was continuously followed by real-time FT-IR spectroscopy (Nicolet ${ }^{\mathrm{TM}}$ iS10, from Thermo Scientific Waltham, MA, USA equipped with a horizontal attachment) at about $790 \mathrm{~cm}^{-1}$.

\subsubsection{Free Radical Photopolymerisation of Acrylate TMPTA}

The experiments were carried out in laminate, the formulations ( $25 \mu \mathrm{m}$ thick) were sandwiched between two polypropylene films to reduce the oxygen inhibition. The evolution of the double bond content was continuously followed by real time FT-IR spectroscopy (Nicolet ${ }^{\mathrm{TM}}$ iS10, from Thermo Scientific Waltham, MA, USA equipped with a horizontal attachment) at about $1634 \mathrm{~cm}^{-1}$.

\subsubsection{Sources of Light for Real-Time Experiments of Photopolymerisation Processes}

The light source for the real-time FT-IR method were the $405 \mathrm{~nm}$ M405L3 Vis-LED and $420 \mathrm{~nm}$ M420L3 Vis-LED diodes (from Thorlabs Inc., Newton, NJ, USA), powered by a DC2200 regulated power supply (from Thorlabs Inc., Newton, NJ, USA). The Vis-LED diode was started $10 \mathrm{~s}$ after the start of spectral registration. The distance between irradiation sources and formulations was $2.1 \mathrm{~cm}$. The incident light intensity at the sample surface was $\mathrm{I}_{0}=17.24\left[\mathrm{~mW} \cdot \mathrm{cm}^{-2}\right]$ for Vis-LED@405 nm, $\mathrm{I}_{0}=14.87$ or $\mathrm{I}_{0}=0.60\left[\mathrm{~mW} \cdot \mathrm{cm}^{-2}\right]$ for Vis-LED@420.

\section{6. $3 D$ Printing}

3D printing experiments were performed using NEJE DK-8-KZ $1000 \mathrm{~mW}$ Laser Engraver Printer with a laser diode at $405 \mathrm{~nm}$ with an intensity of $100 \mathrm{~mW} \cdot \mathrm{cm}^{-2}$ (spot size $\sim 50 \mathrm{~mm}$ ). The photosensitive formulations ( $2 \mathrm{~mm}$ thickness) were deposited onto a microscope slide with a rectangular or round form stuck on it and were polymerized under air. The generated 3D objects were observed thanks to using to an optical stereo microscope (Bresser Advance ICD 10-160_Zoom Stereo-Microscope, Bresser $\mathrm{GmbH}$, Rhede, Germany) and a multifunctional digital microscope Hayear HY-1070, as a light source M365L2 UV-LED (from Thorlabs Inc., Newton, NJ, USA) was used, powered by a DC2200 regulated power supply (from Thorlabs Inc., Newton, NJ, USA).

\section{Conclusions}

In this work, we proposed new thioxanthone-based compounds as sensitizers of iodonium and sulphonium salt for polymerisation processes under visible soft irradiation conditions. The synthesis and properties of thioxanthone derivatives were described. The studied compounds exhibit photoinitiating efficiency when combined with the commercial initiators IOD or TAS for the cationic photopolymerisation of epoxy monomers and for the free-radical polymerisation of acrylates. Moreover, the studied compounds were also applied as components of bimolecular photoinitiating systems with amines: NPG and EDB. Experimental results show that 2,4-diethyl-thioxanthen-9-one derivatives are efficient in photooxidation processes, as well as in photoreduction processes. Additionally, compound $\mathrm{T} 1$ was investigated as an organophotocatalyst for photopolymerisation reactions in three-component initiating systems with onium salts IOD and TAS, amines NPG and EDB and alkyl halide EBPA. The performance of the investigated initiating systems was also tested in 3D printing applications.

\section{Patents}

Patent application P.434493 with priority date 29 June 2020, authors: Joanna Ortyl and Emilia Hola, title: "New derivatives of thioxanthen-9-one, methods of their preparation, new photoinitiating systems for the photoinitiated processes of cationic, radical, thiol-ene and hybrid polymerization, and the use of new derivatives of thioxanthen-9-one and 2,4-diethyl-thioxanthen-9-one". 
Supplementary Materials: The following are available online at http://www.mdpi.com/2073-4344/10/8/903/s1, Schemes S1-S3: Synthetic procedure used to obtain 2,4-diethyl-thioxanthen-9-one derivatives. Figures S1-S5: Normalized excitation and emission spectra for 2,4-diethyl-thioxanthen-9-one derivatives. Figures S6-S14: Cyclic voltammogram curves of the oxidation and reduction processes of 2,4-diethyl-thioxanthen-9-one derivatives. Figures S15 and S16: Cyclic voltammogram curves of the oxidation of EDB and NPG. Figure S17: Cyclic voltammogram curves of the reduction of TAS.

Author Contributions: J.O. conceived the project, designed research and contributed to all aspects of the study, revised the final version of manuscript. E.H. performed synthesis of 2,4-diethylthioxanthone derivatives reported in this work and characterized the chemical structures of investigated compounds by usual techniques, performed all spectroscopic and photopolymerization experiments, prepared all figures, wrote the draft version of the manuscript and assisted in writing and editing the final paper. M.P. performed electrochemical measurements and molecular orbital calculations. All authors have read and agreed to the published version of the manuscript.

Funding: This research was funded by the Foundation for Polish Science (Warsaw, Poland) TEAM TECH Project, Grant number TEAM TECH/ 2016-2/15 (POIR.04.04.00-00-204B/16-00) “Molecular Design, Synthesis and Application of Photoinitiator-Catalysts (PICs) for Photopolymerization Reactions".

Conflicts of Interest: The authors declare no conflict of interest.

\section{References}

1. Chatani, S.; Kloxin, C.J.; Bowman, C.N. The power of light in polymer science: Photochemical processes to manipulate polymer formation, structure, and properties. Polym. Chem. 2014, 5, 2187-2201. [CrossRef]

2. Javadi, A.; Mehr, H.S.; Sobani, M.; Soucek, M.D. Cure-on-command technology: A review of the current state of the art. Prog. Org. Coat. 2016, 100, 2-31. [CrossRef]

3. Hola, E.; Pilch, M.; Galek, M.; Ortyl, J. New versatile bimolecular photoinitiating systems based on amino-: M-terphenyl derivatives for cationic, free-radical and thiol-ene photopolymerization under low intensity UV-A and visible light sources. Polym. Chem. 2020, 11, 480-495. [CrossRef]

4. Nowak, D.; Ortyl, J.; Kamińska-Borek, I.; Kukuła, K.; Topa, M.; Popielarz, R. Photopolymerization of hybrid monomers: Part I: Comparison of the performance of selected photoinitiators in cationic and free-radical polymerization of hybrid monomers. Polym. Test. 2017, 64, 313-320. [CrossRef]

5. Nowak, D.; Ortyl, J.; Kamińska-Borek, I.; Kukuła, K.; Topa, M.; Popielarz, R. Photopolymerization of hybrid monomers, Part II: Determination of relative quantum efficiency of selected photoinitiators in cationic and free-radical polymerization of hybrid monomers. Polym. Test. 2018, 67, 144-150. [CrossRef]

6. Ortyl, J.; Wilamowski, J.; Milart, P.; Galek, M.; Popielarz, R. Relative sensitization efficiency of fluorescent probes/sensitizers for monitoring and acceleration of cationic photopolymerization of monomers. Polym. Test. 2015, 48, 151-159. [CrossRef]

7. Ortyl, J.; Fiedor, P.; Chachaj-Brekiesz, A.; Pilch, M.; Hola, E.; Galek, M. The applicability of 2-amino-4,6-diphenyl-pyridine-3-carbonitrile sensors for monitoring different types of photopolymerization processes and acceleration of cationic and free-radical photopolymerization under near UV light. Sensors 2019, 19, 1668. [CrossRef] [PubMed]

8. Kamińska, I.; Ortyl, J.; Popielarz, R. Applicability of quinolizino-coumarins for monitoring free radical photopolymerization by fluorescence spectroscopy. Polym. Test. 2015, 42, 99-107. [CrossRef]

9. Kostrzewska, K.; Ortyl, J.; Dobosz, R.; Kabatc, J. Squarylium dye and onium salts as highly sensitive photoradical generators for blue light. Polym. Chem. 2017, 8, 3464-3474. [CrossRef]

10. Hola, E.; Topa, M.; Chachaj-Brekiesz, A.; Pilch, M.; Fiedor, P.; Galek, M.; Ortyl, J. New, highly versatile bimolecular photoinitiating systems for free-radical, cationic and thiol-ene photopolymerization processes under low light intensity UV and visible LEDs for 3D printing application. RSC Adv. 2020, 10, 7509-7522. [CrossRef]

11. Fiedor, P.; Pilch, M.; Szymaszek, P.; Chachaj-Brekiesz, A.; Galek, M.; Ortyl, J. Photochemical study of a new bimolecular photoinitiating system for vat photopolymerization 3D printing techniques under visible light. Catalysts 2020, 10, 284. [CrossRef]

12. Lalevée, J.; Fouassier, J.P. (Eds.) Photopolymerisation Initiating Systems, 1st ed.; Royal Society of Chemistry: Croydon, UK, 2018.

13. Dietlin, C.; Schweizer, S.; Xiao, P.; Zhang, J.; Morlet-Savary, F.; Graff, B.; Fouassier, J.P.; Lalevée, J. Photopolymerization upon LEDs: New photoinitiating systems and strategies. Polym. Chem. 2015, 6, 3895-3912. [CrossRef] 
14. Nair, G.B.; Dhoble, S.J. A perspective perception on the applications of light-emitting diodes. Luminescence 2015, 30, 1167-1175. [CrossRef] [PubMed]

15. Mokbel, H.; Toufaily, J.; Hamieh, T.; Dumur, F.; Campolo, D.; Gigmes, D.; Pierre Fouassier, J.; Ortyl, J.; Lalevée, J. Specific cationic photoinitiators for near UV and visible LEDs: Iodonium versus ferrocenium structures. J. Appl. Polym. Sci. 2015, 132,1-10. [CrossRef]

16. Ortyl, J.; Popielarz, R. New photoinitiators for cationic polymerization. Polimery/Polymers 2012, 57, 510-517. [CrossRef]

17. Crivello, J.V. Cationic polymerization-Iodonium and sulfonium salt photoinitiators. In InitiatorsPoly-Reactions_Optical Activity; Springer: Berlin/Heidelberg, Germany, 2005; pp. 1-48. [CrossRef]

18. Dadashi-Silab, S.; Doran, S.; Yagci, Y. Photoinduced Electron Transfer Reactions for Macromolecular Syntheses. Chem. Rev. 2016, 116, 10212-10275. [CrossRef]

19. Crivello, J.P. Photoinitiated cationic polymerization. Ann. Rev. Mater. Sci. 1983, 13, 173-190. [CrossRef]

20. Lewis, F.D.; Lauterbach, R.T.; Heine, H.G.; Hartmann, W.; Rudolph, H. Photochemical alpha Cleavage of Benzoin Derivatives. Polar Transition States for Free-Radical Formation. J. Am. Chem. Soc. 1975, 97, 1519-1525. [CrossRef]

21. Günzler, F.; Wong, E.H.H.; Koo, S.P.S.; Junkers, T.; Christopher, B.K. Quantifying the eficiency of photoinitiation processes in methyl methacrylate free radical polymerization via electrospray ionization mass spectrometry. Macromolecules 2009, 42, 1488-1493. [CrossRef]

22. Voll, D.; Hufendiek, A.; Junkers, T.; Barner-Kowollik, C. Quantifying photoinitiation efficiencies in a multiphotoinitiated free-radical polymerization. Macromol. Rapid Commun. 2012, 33, 47-53. [CrossRef]

23. Stocker, T.; Qin, D.; Plattner, G.K.; Tignor, M.; Allen, S.; Boschung, J.; Nauels, A.; Xia, Y.; Bex, V.; Midgley, P. Summary for policymakers. In Climate Change 2013-The Physical Science Basis: Working Group I Contribution to the Fifth Assessment Report of the Intergovernmental Panel on Climate Change; Cambridge University Press: Cambridge, UK, 2014; pp. 1-30. [CrossRef]

24. Allen, N.S.; Catalina, F.; Green, P.N.; Green, W.A. Photochemistry of carbonyl photoinitiators. Photopolymerisation, flash photolysis and spectroscopic study. Eur. Polym. J. 1986, 22, 49-56. [CrossRef]

25. Gruber, H.F. Photoinitiators for free radical polymerization. Prog. Polym. Sci. 1992, 17, 953-1044. [CrossRef]

26. Temel, G.; Enginol, B.; Aydin, M.; Balta, D.K.; Arsu, N. Photopolymerization and photophysical properties of amine linked benzophenone photoinitiator for free radical polymerization. J. Photochem. Photobiol. A Chem. 2011, 219, 26-31. [CrossRef]

27. Yu, Q.; Nauman, S.; Santerre, J.P.; Zhu, S. UV photopolymerization behavior of dimethacrylate oligomers with camphorquinone/amine initiator system. J. Appl. Polym. Sci. 2001, 82, 1107-1117. [CrossRef]

28. Anderson, D.G.; Davidson, R.S.; Elvery, J.J. Thioxanthones: Their fate when used as photoinitiators. Polymer 1996, 37, 2477-2484. [CrossRef]

29. Fouassier, J.P. Photoinitiation, photopolymerization, and photocuring (fundamentals and applications). IEEE Electr. Insul. Mag. 1996, 12, 36. [CrossRef]

30. Dadashi-Silab, S.; Aydogan, C.; Yagci, Y. Shining a light on an adaptable photoinitiator: Advances in photopolymerizations initiated by thioxanthones. Polym. Chem. 2015, 6, 6595-6615. [CrossRef]

31. Temel, G.; Arsu, N. 2-Methylol-thioxanthone as a free radical polymerization initiator. J. Photochem. Photobiol. A Chem. 2007, 191, 149-152. [CrossRef]

32. Doğruyol, S.K.; Doğruyol, Z.; Arsu, N. Thioxanthone based 9-[2-(methyl-phenyl-amino)-acetyl]-thianaphthacene-12- one as a visible photoinitiator. J. Lumin. 2013, 138, 98-104. [CrossRef]

33. Balta, D.K.; Arsu, N.; Yagci, Y.; Sundaresan, A.K.; Jockusch, S.; Turro, N.J. Mechanism of photoinitiated free radical polymerization by thioxanthone-anthracene in the presence of air. Macromolecules 2011, 44, 2531-2535. [CrossRef]

34. Mutlu, S.; Watanabe, K.; Takahara, S.; Arsu, N. Thioxanthone-anthracene-9-carboxylic acid as radical photoinitiator in the presence of atmospheric air. J. Polym. Sci. Part A Polym. Chem. 2018, 56, 1878-1883. [CrossRef]

35. Balta, D.K.; Temel, G.; Goksu, G.; Ocal, N.; Arsu, N. Thioxanthone-diphenyl anthracene: Visible light photoinitiator. Macromolecules 2012, 45, 119-125. [CrossRef]

36. Karaca, N.; Ocal, N.; Arsu, N.; Jockusch, S. Thioxanthone-benzothiophenes as photoinitiator for free radical polymerization. J. Photochem. Photobiol. A Chem. 2016, 331, 22-28. [CrossRef] 
37. Sevinc, D.; Karasu, F.; Arsu, N. Thioxanthone-benzotriazole: Initiator and stabilizer properties in one component. J. Photochem. Photobiol. A Chem. 2009, 203, 81-84. [CrossRef]

38. Ścigalski, F.; Jankowski, K. Mercaptoalkoxy-thioxanthones as a novel photoinitiator for free radical polymerization. Polym. Bull. 2015, 72, 255-263. [CrossRef]

39. Esen, D.S.; Temel, G.; Balta, D.K.; Allonas, X.; Arsu, N. One-component thioxanthone acetic acid derivative photoinitiator for free radical polymerization. Photochem. Photobiol. 2014, 90, 463-469. [CrossRef]

40. Keskin, S.; Jockusch, S.; Turro, N.J.; Arsu, N. 2-Mercaptothioxanthone as sensitizer and coinitiator for acylphosphine oxide photoinitiators for free radical polymerization. Macromolecules 2008, 41, 4631-4634. [CrossRef]

41. Tar, H.; Sevinc Esen, D.; Aydin, M.; Ley, C.; Arsu, N.; Allonas, X. Panchromatic type II photoinitiator for free radical polymerization based on thioxanthone derivative. Macromolecules 2013, 46, 3266-3272. [CrossRef]

42. Wu, Q.; Xiong, Y.; Liang, Q.; Tang, H. Developing thioxanthone based visible photoinitiators for radical polymerization. RSC Adv. 2014, 4, 52324-52331. [CrossRef]

43. Dogruyol, S.K.; Dogruyol, Z.; Arsu, N. A thioxanthone-based visible photoinitiator. J. Polym. Sci. Part A Polym. Chem. 2011, 49, 4037-4043. [CrossRef]

44. Jiang, X.; Yin, J. Polymeric photoinitiator containing in-chain thioxanthone and coinitiator amines. Macromol. Rapid Commun. 2004, 25, 748-752. [CrossRef]

45. Jiang, X.; Yin, J. Study of macrophotoinitiator containing in-chain thioxanthone and coinitiator amines. Polymer (Guildf.) 2004, 45, 5057-5063. [CrossRef]

46. Yilmaz, G.; Tuzun, A.; Yagci, Y. Thioxanthone-carbazole as a visible light photoinitiator for free radical polymerization. J. Polym. Sci. Part A Polym. Chem. 2010, 48, 5120-5125. [CrossRef]

47. Karaca, N.; Karaca, B.D.; Ocal, N.; Arsu, N. Mechanistic studies of thioxanthone-carbazole as a one-component type II photoinitiator. J. Lumin. 2014, 146, 424-429. [CrossRef]

48. Matsumura, S.; Hlil, A.R.; Lepiller, C.; Gaudet, J.; Guay, D.; Shi, Z.; Holdcroft, S.; Hay, A.S. Stability and Utility of Pyridyl Disulfide Functionality in RAFT and Conventional Radical Polymerizations. J. Polym. Sci. Part A Polym. Chem. 2008, 46, 7207-7224. [CrossRef]

49. Lalevée, J.; Blanchard, N.; Ali Tehfe, M.; Fries, C.; Morlet-Savary, F.; Gigmes, D.; Fouassier, J.P. New thioxanthone and xanthone photoinitiators based on silyl radical chemistry. Polym. Chem. 2011, 2, 1077-1084. [CrossRef]

50. Alonso, R.; Bach, T. A chiral thioxanthone as an organocatalyst for enantioselective [2+2] photocycloaddition reactions induced by visible light. Angew. Chem. Int. Ed. 2014, 53, 4368-4371. [CrossRef]

51. Dansholm, C.N.; Junker, A.K.R.; Nielsen, L.G.; Kofod, N.; Pal, R.; Sørensen, T.J. $\pi$-Expanded ThioxanthonesEngineering the Triplet Level of Thioxanthone Sensitizers for Lanthanide-Based Luminescent Probes with Visible Excitation. Chempluschem 2019, 84, 1778-1788. [CrossRef]

52. Xiao, P.; Lalevée, J.; Zhao, J.; Stenzel, M.H. N-Vinylcarbazole as Versatile Photoinaddimer of Photopolymerization under Household UV LED Bulb (392 nm). Macromol. Rapid Commun. 2015, 36, 1675-1680. [CrossRef]

53. Zhang, J.; Zivic, N.; Dumur, F.; Guo, C.; Li, Y.; Xiao, P.; Graff, B.; Gigmes, D.; Fouassier, J.P.; Lalevée, J. Panchromatic photoinitiators for radical, cationic and thiol-ene polymerization reactions: A search in the diketopyrrolopyrrole or indigo dye series. Mater. Today Commun. 2015, 4, 101-108. [CrossRef]

54. Mousawi, A.A.; Dietlin, C.; Graff, B.; Morlet-Savary, F.; Toufaily, J.; Hamieh, T.; Fouassier, J.P.; Chachaj-Brekiesz, A.; Ortyl, J.; Lalevée, J. Meta-Terphenyl Derivative/Iodonium Salt/9H-Carbazole-9-ethanol Photoinitiating Systems for Free Radical Promoted Cationic Polymerization upon Visible Lights. Macromol. Chem. Phys. 2016, 217, 1955-1965. [CrossRef]

55. Al, M.A.; Kermagoret, A.; Versace, D.L.; Toufaily, J.; Hamieh, T.; Graff, B.; Dumur, F.; Gigmes, D.; Fouassier, J.P.; Lalevée, J. Copper photoredox catalysts for polymerization upon near UV or visible light: Structure/reactivity/efficiency relationships and use in LED projector 3D printing resins. Polym. Chem. 2017, 8, 568-580. [CrossRef]

56. Hola, E.; Ortyl, J.; Jankowska, M.; Pilch, M.; Galek, M.; Morlet-Savary, F.; Graff, B.; Dietlin, C.; Lalevée, J. New bimolecular photoinitiating systems based on terphenyl derivatives as highly efficient photosensitizers for 3D printing application. Polym. Chem. 2020, 11, 922-935. [CrossRef] 
57. Mousawi, A.A.; Garra, P.; Dumur, F.; Bui, T.T.; Goubard, F.; Toufaily, J.; Hamieh, T.; Graff, B.; Gigmes, D.; Fouassier, J.P.; et al. Novel carbazole skeleton-based photoinitiators for led polymerization and LED projector 3D printing. Molecules 2017, 22, 2143. [CrossRef]

58. Sundell, P.-E.; Jösson, S.; Hult, A. Photo-redox induced cationic polymerization of divinyl ethers. J. Polym. Sci. Part A Polym. Chem. 1991, 29, 1525-1533. [CrossRef]

59. Popal, M.; Volk, J.; Leyhausen, G.; Geurtsen, W. Cytotoxic and genotoxic potential of the type I photoinitiators BAPO and TPO on human oral keratinocytes and V79 fibroblasts. Dent. Mater. 2018, 34, 1783-1796. [CrossRef]

60. Van Landuyt, K.L.; Krifka, S.; Hiller, K.A.; Bolay, C.; Waha, C.; Van Meerbeek, B.; Schmalz, G.; Schweikl, H. Evaluation of cell responses toward adhesives with different photoinitiating systems. Dent. Mater. 2015, 31, 916-927. [CrossRef]

61. Rehm, D.; Weller, A. Kinetics of Fluorescence Quenching by Electron and H-Atom Transfer. Isr. J. Chem. 1970, 8, 259-271. [CrossRef]

62. Nzulu, F.; Telitel, S.; Stoffelbach, F.; Graff, B.; Morlet-Savary, F.; Lalevée, J.; Fensterbank, L.; Goddard, J.P.; Ollivier, C. A dinuclear gold(i) complex as a novel photoredox catalyst for light-induced atom transfer radical polymerization. Polym. Chem. 2015, 6, 4605-4611. [CrossRef]

63. Romańczyk, P.P.; Kurek, S.S. The Reduction Potential of Diphenyliodonium Polymerisation Photoinitiator Is Not -0.2 V vs. SCE. A Computational Study. Electrochim. Acta 2017, 255, 482-485. [CrossRef]

64. Strehmel, B.; Ernst, S.; Reiner, K.; Keil, D.; Lindauer, H.; Baumann, H. Application of nir-photopolymers in the graphic industry: From physical chemistry to lithographic applications. Z. Phys. Chem. 2014, 228, 129-153. [CrossRef]

(C) 2020 by the authors. Licensee MDPI, Basel, Switzerland. This article is an open access article distributed under the terms and conditions of the Creative Commons Attribution (CC BY) license (http://creativecommons.org/licenses/by/4.0/). 